\title{
The (pro)renin receptor mediates constitutive PLZF-independent pro-proliferative effects which are inhibited by bafilomycin but not genistein
}

\author{
SEBASTIAN KIRSCH ${ }^{1}$, EVA SCHREZENMEIER ${ }^{2}$, SABRINA KLARE $^{2}$, DANIELA ZAADE $^{2}$, KERSTIN SEIDEL $^{2}$, \\ JENNIFER SCHMITZ ${ }^{2}$, SARAH BERNHARD ${ }^{2}$, DILYARA LAUER ${ }^{1}$, MARK SLACK $^{3}$, PETRA GOLDIN-LANG ${ }^{1}$, \\ THOMAS UNGER ${ }^{4}$, FRANK S. ZOLLMANN ${ }^{1}$ and HEIKO FUNKE-KAISER ${ }^{1}$ \\ ${ }^{1}$ Institute of Laboratory Medicine, Clinical Chemistry and Pathobiochemistry, Charité - Universitätsmedizin Berlin, \\ ${ }^{2}$ Center for Cardiovascular Research (CCR)/Institute of Pharmacology, Charité - Universitätsmedizin Berlin, Berlin; \\ ${ }^{3}$ Evotec AG, Hamburg, Germany; ${ }^{4}$ School for Cardiovascular Diseases (CARIM), \\ Maastricht University, Maastricht, The Netherlands
}

Received December 2, 2013; Accepted December 23, 2013

DOI: $10.3892 /$ ijmm.2014.1624

\begin{abstract}
The (pro)renin receptor [(P)RR] is crucial for cardio-renal pathophysiology. The distinct molecular mechanisms of this receptor are still incompletely understood. The (P)RR is able to interact with different signalling proteins such as promyelocytic leukemia zinc finger protein (PLZF) and Wnt receptors. Moreover, domains of the (P)RR are essential for V-ATPase activity. V-ATPase- and Wnt-mediated effects imply constitutive, i.e., (pro)renin-independent functions of the (P)RR. Regarding ligand-dependent (P)RR signalling, the role of prorenin glycosylation is currently unknown. Therefore, the aim of this study was to analyse the contribution of constitutive (P)RR activity to its cellular effects and the relevance of prorenin glycosylation on its ligand activity. We were able to demonstrate that high glucose induces $(\mathrm{P}) \mathrm{RR}$ signal transduction whereas deglycosylation of prorenin abolishes its intrinsic activity in neuronal and epithelial cells. By using siRNA against (P)RR or PLZF as well as the PLZF translocation blocker genistein and the specific V-ATPase inhibitor bafilomycin, we were able to dissect three distinct sub-pathways downstream of the (P)RR. The V-ATPase function is ligandindependently associated with strong pro-proliferative effects whereas prorenin causes moderate proliferation in vitro. In contrast, PLZF per se [i.e., in the absence of (pro)renin] does not interfere with cell number.
\end{abstract}

Correspondence to: Dr Heiko Funke-Kaiser, Institute of Laboratory Medicine, Clinical Chemistry and Pathobiochemistry, Charité - Universitätsmedizin Berlin, Augustenburger Platz 1, D-13353 Berlin, Germany

E-mail: heiko@funke-kaiser.com

Key words: (pro)renin receptor, small-molecule drug, cancer, PLZF, glucose

\section{Introduction}

The (pro)renin receptor [(P)RR also called RER] constitutes a novel component of the renin-angiotensin system (RAS) and exerts pivotal functions in cardio-renal pathophysiology since it is linked to angiotensin II-dependent and also angiotensin II-independent effects (1). Binding of renin to the (P)RR increases its catalytic efficiency 4- to 5-fold, whereas binding of prorenin non-proteolytically demasks the catalytic activity of prorenin (2).

Various research studies have demonstrated that the competitive inhibition of the binding of (pro)renin to the (P)RR by parenteral application of a decoy peptide, which is derived from the prosegment of prorenin, prevents the development of diabetic nephropathy and reduces cardiac fibrosis (3-6). Importantly, (pro)renin receptor blockade by these decoys is also effective in angiotensin AT1 receptor (AT1R)-knockout mice (7) and can even reverse renal damage caused by diabetes (8).

Nevertheless, a number of authors were not able to observe positive effects of these peptides $(9,10)$. These controversies may be explained by the prorenin-renin ratio since the decoys were effective in high prorenin/low renin models $(1,11)$, and/ or by the length of treatment based on the observation that renoprotective effects were able to be observed after 12 weeks even in a high renin Goldblatt model $(12,13)$.

In addition, the effectiveness of the decoy peptides regarding reduction in weight gain, serum triglycerides and hyperinsulinemia has been shown in animals fed with a high fat/high carbohydrate diet $(14,15)$. Beneficial effects were also observed concerning diabetic retinopathy (16-18). Recently, it was demonstrated that the $(\mathrm{P}) \mathrm{RR}$ was upregulated at the mRNA and protein levels in murine hearts after myocardial infarction as well as in patients with dilated cardiomyopathy (19) further supporting the pathophysiological importance of this receptor. Consistently, at the molecular level, activation of the (P)RR by (pro)renin is associated with a detrimental transcriptional signature, e.g. linked to cardiac hypertrophy, cardiac and renal 
cell death (20). Moreover, the (P)RR is upregulated on the mRNA and protein levels in the hearts and kidneys of diabetic rats $(21,22)$.

Our research group revealed a novel signal transduction pathway involving the physical interaction between the (P)RR and the transcription factor promyelocytic leukemia zinc finger protein (PLZF). Upon stimulation of the (P)RR with renin or prorenin, PLZF was found to translocate into the nucleus and repress the RER promoter itself $(23,24)$. Regarding the ligand level, different renin glyocoforms, which are likely linked to the differential plasma half-lives, have been previously described (25).

In addition, renin-independent functions of the (P)RR have been recently described (26). In this context, it is important to note that the $(\mathrm{P}) \mathrm{RR}$ protein consists of an evolutionarily conserved part (comprising the C-terminal 69-100 amino acids) and a large $\mathrm{N}$-terminal (pro)renin binding domain $(1,27)$. The ancient part is identical to the vacuolar proton-translocating ATPase (V-ATPase) membrane sector-associated protein M8-9 $(28,29)$. Therefore, it has been suggested that the gene encoding the (P)RR results from a gene fusion (30). Nevertheless, these parts can be separated at the protein level again based on the identification of a soluble (P)RR isoform [s(P)RR] which nearly represents the extracellular part (31). The $\mathrm{s}(\mathrm{P}) \mathrm{RR}$ is generated by the action of furin and/or ADAM proteases $(31,32)$.

Considering the different protein isoforms of the (P)RR, it has been shown that the specific V-ATPase inhibitor bafilomycin A1 inhibits (P)RR signalling (29). In addition, the nuclear translocation of PLZF, in the context of the angiotensin AT2 receptor (AT2R), is inhibited by the small molecule genistein (33). Currently, genistein and bafilomycin are the only drug-like, commercially available small molecules directly interfering with (P)RR signal transduction.

Therefore, the aim of the present study was to analyse (pro)renin-independent, i.e., constitutive, activity of the (P)RR, the transcriptional and isoform-specific regulation of this receptor as well as the effects of genistein and bafilomycin on its signal transduction. Since constitutive receptor activity does not exclude ligand effects (34) and may be unveiled by inactivating post-translational modifications of the ligand, we also analysed the effects of prorenin deglycosylation.

\section{Materials and methods}

Cell culture. B-16V (mouse melanoma) and KELLY (human neuroblastoma) cells (both from DSMZ, Braunschweig, Germany) were grown in RPMI-1640 medium (Life Technologies, Darmstadt, Germany). HeLa-S3 (human cervical carcinoma), HEK293 (human embryonic kidney) (both from DSMZ) and HEK293T cells [American Type Culture Collection (ATCC), Manassas, VA, USA] were cultivated in DMEM high glucose (Life Technologies). Flp-In-293 HEK cells (Invitrogen, Karlsruhe, Germany) were grown in DMEM high glucose supplemented with $2 \mathrm{mM}$ glutamine (PAA, Pasching, Austria). All media contained 10\% fetal bovine serum (Life Technologies), $100 \mathrm{U} / \mathrm{ml}$ penicillin and $100 \mu \mathrm{g} / \mathrm{ml}$ streptomycin (A2212; Biochrom, Berlin, Germany). If the experimental conditions were modified the changes are described in the Results section. All cell lines were cultivated without addition of an angiotensin AT1 receptor blocker (ARB) and, if not otherwise specified, without starving in a humidified incubator with $5 \% \mathrm{CO}_{2}$ at $37^{\circ} \mathrm{C}$.

All experiments using the stably transfected HeLa cell line were performed in 48-well plates (BD Falcon, Franklin Lakes, NJ, USA). For all transient transfections of (P)RR promoter constructs and (P)RR expression vectors, 24-well plates (BD Falcon; from Corning Inc., Corning, NY, USA) (in the case of KELLY cells) and 6-well plates (BD Falcon), respectively, were used. Prorenin was obtained from Innovative Research (Novi, MI, USA). Bafilomycin A1 (Enzo Life Science, Lörrach, Germany) and genistein (Carl Roth GmbH, Karlsruhe, Germany) were dissolved in $1 \%$ DMSO final if not otherwise stated.

Subcloning and transient transfection experiments. The full-length human (P)RR coding sequence was cloned into pEGFP-N1 and pEGFP-C3 vectors (Clontech, Mountain View, CA, USA) as described previously (23). A construct containing $1,100 \mathrm{bp}$ (directly upstream of the translational start site) of the human (P)RR was subcloned into the pGL4.14 luciferase vector (Promega, Mannheim, Germany) using previously published primers (23). Transient transfection experiments of these expression vectors were perfomed using Genejuice (Merck, Darmstadt, Germany) or Turbofect (Fermentas, St. Leon-Rot, Germany) transfection reagents according to manufacturers' protocols with $25 \mathrm{ng}$ DNA $/ \mathrm{cm}^{2}$.

SiRNA experiments were performed with siRNA against (P)RR [5'-gcuccguaaucgccuguuu-3' (sense strand); $20 \mathrm{nM}$ final] or scrambled control siRNA [5'-uuuaccgucgecuugagcu-3' (sense strand)] (Eurogentec, Köln, Germany) and against PLZF [5'-ccagcaagauguuugagau-3' (sense strand); $50 \mathrm{nM}$ ] or scrambled control siRNA [5'-ucucgcagugacuauacau-3' (sense strand)] (Eurogentec), respectively, using HiPerfect (Qiagen, Hilden, Germany). General efficacy of siRNA-mediated knockdown was controlled in KELLY cells by real-time polymerase chain reaction (PCR) ((P)RR mRNA was decreased to $10-30 \%$ relative to the scrambled control) and Western blotting (RER protein was decreased to $\sim 40 \%$ relative to the scrambled control) and in double-stably transfected HeLa cells by Western blotting.

Generation of stable cell lines. To measure the activity of the (P)RR, a double-stable, double-monoclonal HeLa cell line was generated using the human (P)RR promoter/pGL4.14 (firefly) and pGL4.79 (Renilla) plasmids (Promega). The (P) RR promoter sequence and the assay principle were based on Schefe et al (23) and on a patent application of our group (EP 1890152 A1 or PCT WO 2008/019735 A9). The Renilla luciferase activity served for standardisation. After the first transfection (pGL4.14) cells were selected using hygromycin B $(250 \mu \mathrm{g} / \mathrm{ml}$ medium; PAA) and monoclonalised using cloning cylinders (C7983; Sigma-Aldrich, Steinheim, Germany). After the second transfection (pGL4.79) selection was performed by addition of G-418 sulphate (500 $\mu \mathrm{g} / \mathrm{ml}$ medium; PAA) followed by monoclonalisation.

A prorenin-overexpressing and prorenin-secreting HEK293 cell line was generated using the Flp-In system (Invitrogen) and an expression vector (pcDNA5/FRT) encoding preprorenin fused to a C-terminal $\mathrm{His}_{10}$-tag. 
Fractionated protein extraction. Nuclear and cytosolic proteins were isolated as described previously (35). Nuclear fractions were controlled by Wsestern blotting using an antibody against TFIID as described below.

Protein purification and prorenin deglycosylation. His - $_{10}$-tagged prorenin was purified via metal affinity chromatography as follows. Flp-In-293-HEK cells stably transfected with an expression vector encoding C-terminally $\mathrm{His}_{10}$-tagged preprorenin were cultured without starving in 1 or $4.5 \mathrm{~g} / 1$ glucose concentrations for two weeks followed by a two-day serum-free period to exclude interference of serum proteins before collection of the supernatant for affinity chromatography of prorenin. A gravity column (Empty Disposable PD-10 Column, 17-043501; GE Healthcare, Munich, Germany) was loaded with $5 \mathrm{ml}$ of a cobalt matrix (Talon Metal Affinity Resin; Clontech, Saint-Germain-en-Laye, France) and equilibrated with $20 \mathrm{ml}$ washing buffer (50 $\mathrm{mM}$ sodium dihydrogen phosphate, $300 \mathrm{mM}$ sodium chloride, $\mathrm{pH}$ 8.0). Two hundred milliliters of the cell culture supernatant was loaded on the column. The flow-through was discarded. The matrix was washed with washing buffer containing $10 \mathrm{mM}$ imidazole (Sigma-Aldrich). Afterwards, prorenin was eluted with the same buffer but with $250 \mathrm{mM}$ imidazole. Ten fractions each $2 \mathrm{ml}$ were collected and analysed by sodium dodecyl sulfate-polyacrylamide gel electrophoresis (SDS-PAGE) and Coumassie staining. The pure, prorenin-containing fractions were pooled and dialysed in 3 liters of phosphate-buffered saline (PBS) overnight at $4^{\circ} \mathrm{C}$. Finally, the protein solution was concentrated using filter devices excluding proteins $<30 \mathrm{kDa}$ (Amicon Ultra $0.5 \mathrm{ml}$; Millipore $\mathrm{GmbH}$, Schwalbach, Germany). The concentration was determined with UV absortion spectrometry (ND-1000; PeqLab, Erlangen, Germany).

Purified prorenin and a commercially obtained prorenin (from Innovative Reseach) were deglycosylated using N-glycosidase F (11365185001; Roche, Mannheim, Germany), which does not exhibit proteolytic activity, for $2 \mathrm{~h}$ and resolved via SDS-PAGE followed by Coomassie staining.

Real-time PCR. Reverse transcription was performed using M-MLV reverse transcriptase (RNase $\mathrm{H}$ minus; Promega) and $1 \mu \mathrm{g}$ RNA. PCR was performed applying Go-Taq qPCR Master Mix (Promega) and the following primer pairs: 5'-ATTGGC CTATACCAGGAGAG-3' (forward) and 5'-TTCCCCATAAC GCTTCCCAA-3' (reverse) for (P)RR and 5'-CCGCAGCTAGG AATAATGGAATA-3' (forward) and 5'-TCTAGCGGCGCA ATACGAAT-3' (reverse) for 18S rRNA. A reaction without addition of reverse transcriptase served as the negative control. The PCR reactions were run on a Stratagene Mx3000P (Stratagene, La Jolla, CA, USA).

Western blotting. Immunoblotting was performed as previously described (36) but using a cell lysis buffer containing 1X PBS (pH 7.2, without calcium and magnesium; Invitrogen), $1 \%$ Nonidet P-40, $0.5 \%$ sodium deoxycholate, $0.1 \%$ sodium dodecyl sulfate (SDS) (all from Sigma-Aldrich) and Complete EDTA-free cocktail tablets (Roche). The following primary antibodies were used: anti-PLZF (ab39354; Abcam, Cambridge, UK), anti-GFP (sc-8334; Santa Cruz Biotechnology, Inc., Heidelberg, Germany), anti-TFIID [TATA box-binding protein
(TBP)] (sc-273; Santa Cruz Biotechnology, Inc.), anti-(P)RR (ATP6AP2; HPA003156; Sigma-Aldrich), anti-actin (sc-1615; Santa Cruz Biotechnology, Inc.) and anti-GAPDH (MAB374, Chemicon/Merck Millipore, Billerica, MA, USA). Detection of the horseradish peroxidase (HRP)-labelled secondary antibody was performed with an enhanced chemiluminescence (ECL) reagent containing a 1:1 mixture of solution A [100 mM Tris base (pH 8.5), $2.5 \mathrm{mM}$ luminol (Sigma-Aldrich), $0.4 \mathrm{mM}$ $p$-coumaric acid (Sigma-Aldrich)] and solution B [100 mM Tris base $\left(\mathrm{pH} \mathrm{8.5)}, 0.02 \% \mathrm{H}_{2} \mathrm{O}_{2}\right.$ ]. Proteins were quantified using a Bradford assay (Roti-Nanoquant; Carl Roth). Cell culture supernatants were concentrated using Centriprep ${ }^{\circledR}$ $10 \mathrm{~K}$ columns followed by Amicon Ultra 3K columns (both obtained from Merck Millipore, Darmstadt, Germany) before Western blotting. Densitometric analysis was carried out using ImageJ $1.42 q$ software (National Institutes of Health, USA).

Reporter gene assays. Promoter reporter assays regarding stable and transient transfections were performed using the Dual-Luciferase Reporter ${ }^{\circledR}$ assay system (Promega).

For transient transfections, relative luciferase activity (RLA), defined as the mean value of the firefly luciferase/Renilla luciferase ratios of each construct related to the insertless reporter plasmid pGL4.14, served as read-out. Regarding the stable transfection, the firefly/Renilla ratio served as read-out.

Cellular phenotypic assays. Cellular proliferation was measured using the BrdU colorimetric cell proliferation ELISA (Roche). Mitochondrial dehydrogenase activity was determined via the Cell Proliferation Assay XTT (AppliChem, Darmstadt, Germany). Cellular ATP concentrations were analysed using the CellTiter-Glo Luminescent Cell Viability Assay (Promega). The Bradford assay was obtained commercially (Roti-Nanoquant; Carl Roth).

To measure lactate dehydrogenase (LDH) activity in the cell culture supernatant, $50 \mu \mathrm{l}$ medium, $200 \mu \mathrm{l}$ NADH buffer [0.2 mM $\beta$-nicotinamide adenine dinucleotide (reduced disodium salt hydrate; Sigma-Aldrich), 0.1 M potassium hydrogen phosphate buffer ( $\mathrm{pH}$ 7.4)] and, to start the reaction, $25 \mu 1$ pyruvate buffer [22.7 mM sodium pyruvate (Sigma-Aldrich), $0.1 \mathrm{M}$ potassium hydrogen phosphate buffer ( $\mathrm{pH}$ 7.4)] were mixed. After $10 \mathrm{sec}$, NADH was quantified photometrically at $340 \mathrm{nM}(10$ times every $10 \mathrm{sec})$ in a 96-well plate reader.

For the staining of acidic cell organelles (e.g. lysosomes or peroxisomes) HeLa cells were seeded $24 \mathrm{~h}$ before stimulation in black 96-well plates (Cellstar MicroClear; Greiner, Frickenhausen, Germany). After $1 \mathrm{~h}$ prestimulation with genistein or bafilomycin A1, the dye (LysoTracker Red DND-99; Life Technologies) was added to the culture medium ( $75 \mathrm{nM}$ final) for $1 \mathrm{~h}$. After replacement of the supernatant by serum- and phenol red-free medium, measurement was carried out according to the manufacturer's instructions using a fluorescence plate reader (Mithras 940; Berthold, Bad Wildbad, Germany).

Statistical analysis. For comparisons of two interventions including siRNA effects under DMSO control (Fig. 2A) a two-tailed, unpaired t-test was applied. Regarding multiple comparisons, a one-way analysis of variance (ANOVA) with Bonferroni post-hoc adjustment was performed. Statistical 
significance was assumed at $\mathrm{p}<0.05$ for t-test and ANOVA. Concerning plotting of the dose-response curves, a sigmoidal regression analysis was used.

\section{Results}

Effects of genistein, bafilomycin and siRNA interventions on $(P) R R$ promoter activity and $(P) R R$ expression. We previously demonstrated that PLZF is a crucial adapter protein of the (P)RR and its own promoter (23). Other studies have shown that the nuclear translocation of PLZF is inhibited by genistein (33) and that bafilomycin reduces (P)RR signal transduction (29). Therefore, we aimed to ascertain whether genistein, bafilomycin or siRNA against pathway components affects (P)RR promoter activity. As expected, siRNA knockdown of (P)RR and PLZF both significantly derepressed (P)RR promoter activity (Fig. 1). In addition, genistein increased (P)RR promoter activity, whereas bafilomycin had a minor effect (Fig. 2A and B). However, ANOVA using the pooled data shown in Fig. 2A and B indicated that both bafilomycin concentrations significantly increased promoter activity ( $\mathrm{p}<0.01$ for $0.1 \mu \mathrm{M}$ and $\mathrm{p}<0.001$ for $1 \mu \mathrm{M}$ ). Moreover, siRNA against (P)RR and also PLZF caused a derepression of (P)RR promoter activity in the context of coincubations (Fig. 2A) consistent with a repressive role of the (P)RR-PLZF pathway on the (P)RR promoter (23). Importantly, the effect of siRNA against PLZF was abolished by genistein (Fig. 2A) and bafilomycin (Fig. 2B), whereas both substances did not inhibit the effect of siRNA against (P)RR (Fig. 2A and B).

In addition, the $\mathrm{EC}_{50}$ value of genistein was determined showing a potency of $2-4 \mu \mathrm{M}$ regarding promoter activation (Fig. 2C). In addition, a non-sigmoidal concentration-response relationship was also observed concerning the effects of bafilomycin on (P)RR promoter activity (data not shown).

Finally, we analysed whether the effects of genistein and bafilomycin can also be observed at the endogenous transcript level. Both interventions significantly increased (P)RR mRNA after $12 \mathrm{~h}$ (Fig. 2D) when effects on cell number are unlikely.

Additionally, the effects of genistein and bafilomycin on the protein level were analysed with respect to full-length and soluble (P)RR. After 12 and $24 \mathrm{~h}$ of incubation and upon examination of the total cellular lysates, treatment with bafilomycin but not genistein significantly increased soluble (P)RR (Fig. 2E). Consistently, a significantly increased s(P)RR level was observed in the cellular supernatant following incubation with bafilomycin (Fig. 2F).

In this context, it is important to note that the antibody used in Fig. 2E and F only detects the N-terminal part of the (P)RR, i.e., full-length and $s(\mathrm{P}) \mathrm{RR}$, but not the V-ATPaseassociated isoform.

Effects of glucose on $(P) R R$ promoter activity and $(P) R R$ isoform expression. Based on the pathophysiological role of the (P)RR in diabetic nephropathy, we examined its promoter regulation using different glucose conditions. High glucose increased basal (P)RR promoter activity $\sim$ 3-fold (Fig. 3A). Strikingly, prorenin decreased (P)RR promoter activity only under high glucose conditions whereas an inverse response was observed in the cells cultured in a physiological glucose concentration (Fig. 3A).

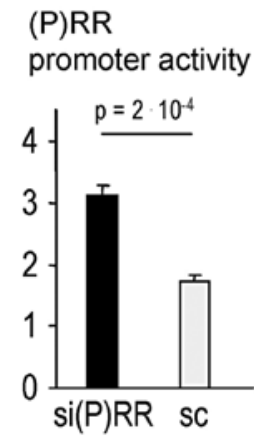

(P)RR

promoter activity

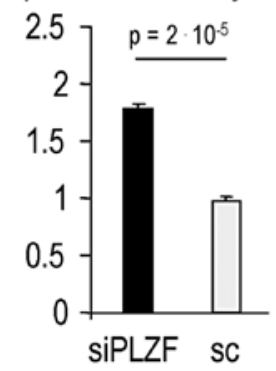

Figure 1. Effects of siRNA against promyelocytic leukemia zinc finger protein $(\mathrm{PLZF})$ or the (pro)renin receptor $[(\mathrm{P}) \mathrm{RR}]$ on $(\mathrm{P}) \mathrm{RR}$ promoter activity. HeLa cells double-stably transfected with the $(\mathrm{P}) \mathrm{RR}$ promoter luciferase constructs were transfected with siRNA against $(\mathrm{P}) \mathrm{RR}[\mathrm{si}(\mathrm{P}) \mathrm{RR}]$ or against PLZF (siPLZF) ( $\mathrm{n}=3$ for each intervention), respectively. Scrambled siRNA (sc) served as the control. Cells were cultured in $4.5 \mathrm{~g} / 1$ glucose without (pro)renin coincubation.

Since the (P)RR is known to be expressed in different protein isoforms, we ascertained whether glucose and bafilomycin also affect these protein identities of the (P)RR. For this purpose, two expression vectors encoding full-length $(\mathrm{P}) \mathrm{RR}$ $\mathrm{N}$ - or C-terminally fused to GFP, respectively, were transiently transfected into wild-type HeLa and wild-type HEK293T cells (Fig. 3B). Regarding specificity, the V-ATPase isoform can only be detected with the anti-GFP antibody after transfection of a C-terminally tagged (P)RR construct since the V-ATPase domain [ 9 $\mathrm{kDa}(37)]$ within the full-length (P)RR [ 38-39 $\mathrm{kDa}(23)]$ is located at the C-terminus. High glucose strongly increased full-length (P)RR in HeLa but not in HEK cells. Bafilomycin, in contrast to genistein, caused a relative shift from the full-length isoform to the V-ATPase isoform in HeLa cells due to a decreased abundance of the full-length form (Fig. 3B).

Effects of glucose on prorenin glycosylation. To ascertain whether high glucose directly affects the glycosylation of the ligand prorenin, we cultured HEK cells stably overexpressing prorenin in high or (relatively) low glucose medium (Fig. 4). The results revealed that HEK cells exhibit the ability to glycosylate prorenin. Furthermore, the two previously described $\mathrm{N}$-glyosylation sites of prorenin (38) were confirmed as indicated by the double band in the presence of the glycosidase. Importantly, high glucose did not alter the glycosylation pattern of prorenin (Fig. 4).

Effects of prorenin glycosylation on $(P) R R$ promoter activity. We next aimed to ascertain whether deglycosylation impacts the ligand activity of prorenin in transiently transfected promoter assays with a sufficient transfection efficiency (as indicated by a firefly signal of the insertless control vector over 1,000 counts) and with a full deglycosylation of both asparagines (as confirmed by SDS-PAGE). As expected based on our previous results $(23,24)$, native prorenin significantly repressed (P)RR promoter activity (Fig. 5A). Complete deglycosylation, as confirmed by SDS-PAGE, abolished this repressive effect (Fig. 5A).

Similar results were also obtained for neuronal KELLY cells. Native prorenin strongly repressed (P)RR promoter 
A

(P)RR

promoter activity

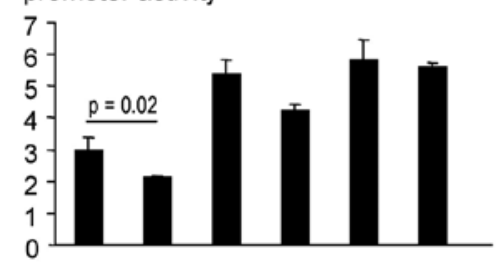

siPLZF

scrambled

DMSO

genistein $10 \mu \mathrm{M}$

genistein $100 \mu \mathrm{M}$

B

\section{(P)RR}

promoter activity

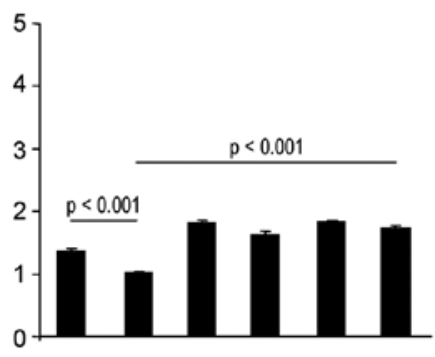

siPLZF

scrambled

DMSO

bafilomycin $0.1 \mu \mathrm{M}$

bafilomycin $1 \mu \mathrm{M}$
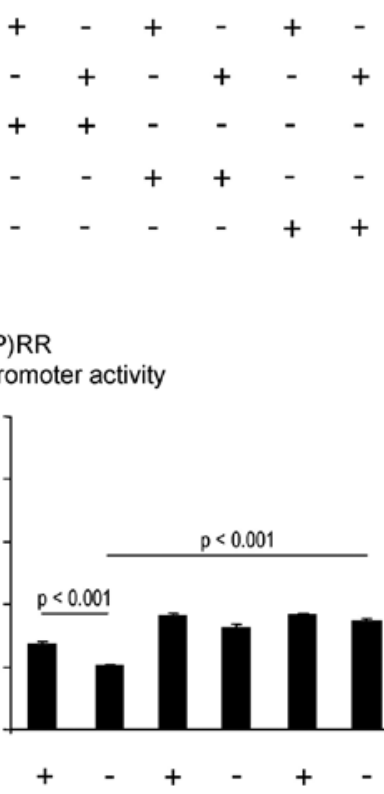

$-+-+-+$

$++-\quad-\quad-$ $+\quad+-\quad-\quad-$

\section{(P)RR}

promoter activity

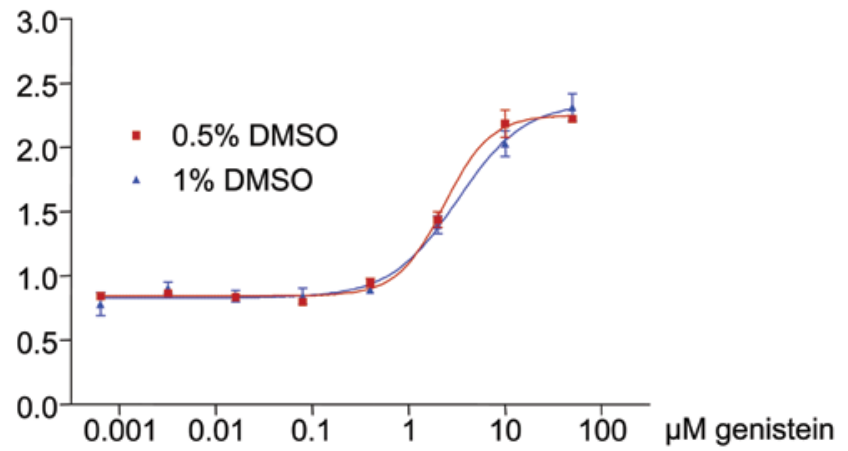

(P)RR

promoter activity

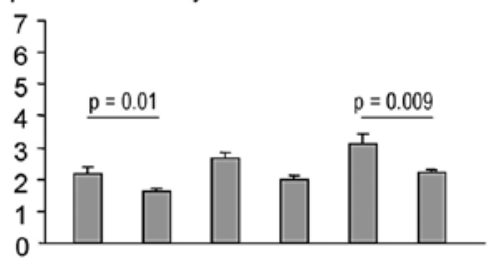

si(P)RR

scrambled

DMSO

bafilomycin $0.1 \mu \mathrm{M}$ -

bafilomycin $1 \mu \mathrm{M}$ -
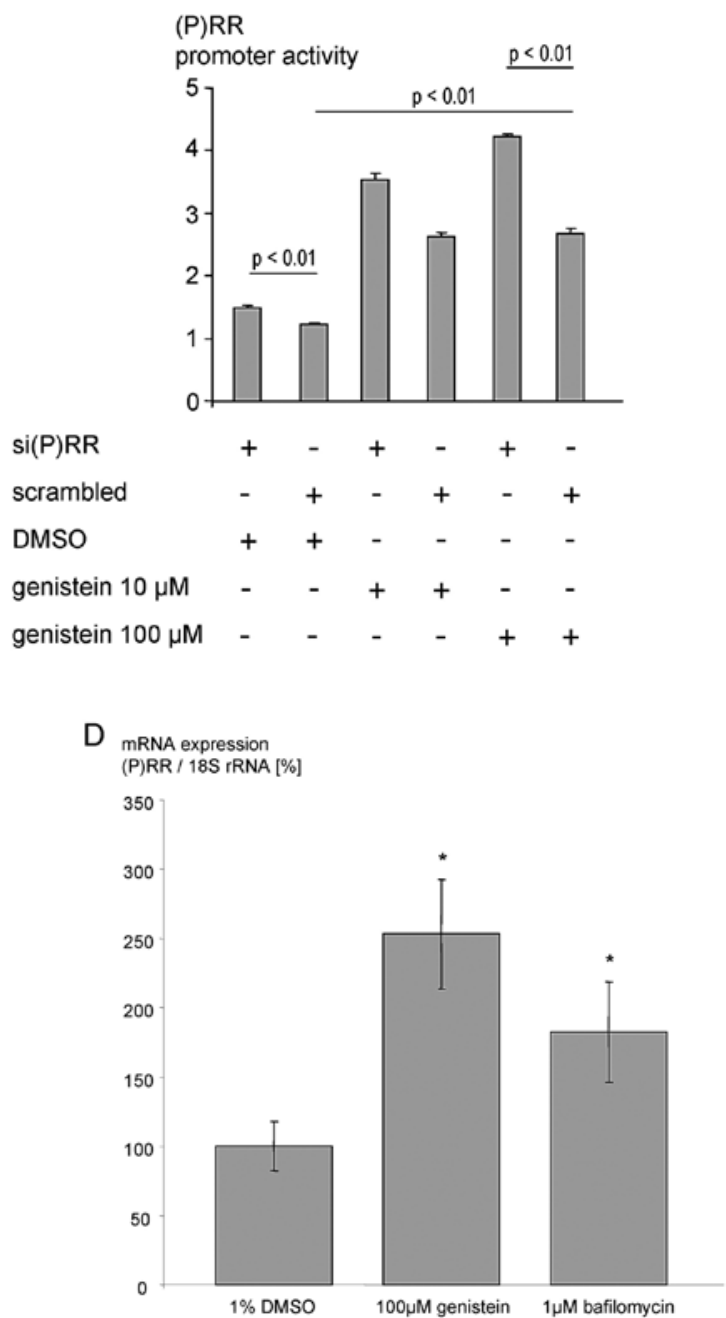

Figure 2. Effects of genistein, bafilomycin and siRNA against promyelocytic leukemia zinc finger protein (PLZF) or the prorenin receptor $[(\mathrm{P}) \mathrm{RR}]$ on $(\mathrm{P})$ RR promoter activity and mRNA levels. (A and B) HeLa cells double-stably transfected with (P)RR promoter luciferase constructs were cultured in $4.5 \mathrm{~g} / 1$ glucose ( $\mathrm{n}=3$ for each intervention). Incubation times were $48 \mathrm{~h}$ for the siRNAs, and $24 \mathrm{~h}$ for genistein and bafilomycin. (C) Dose-response curve of genistein in double-stably transfected HeLa cells. (D) Double-stably transfected HeLa cells were treated with genistein or bafilomycin for $12 \mathrm{~h}$ followed by real-time polymerase chain reaction (PCR). Data represent the mean expression level of (P)RR mRNA standardised to 18S rRNA expression ( \pm standard deviation) of three independent measurements per cDNA (technical triplicates) calculated according to the $\Delta \Delta \mathrm{Ct}$ method. The expression ratio of DMSO was set to $100 \%$. p $\mathrm{p}<0.05$ according to ANOVA.

activity. Deglycosylation of both asparagines of prorenin abolished the ability to repress the (P)RR promoter, whereas a mixture of fully deglycosylated and partially deglycosyl- ated (i.e., one of the two glycosylation sites is completely deglycosylated) prorenin exhibited intermediate repressive effects (Fig. 5B). 
$\mathrm{E}$
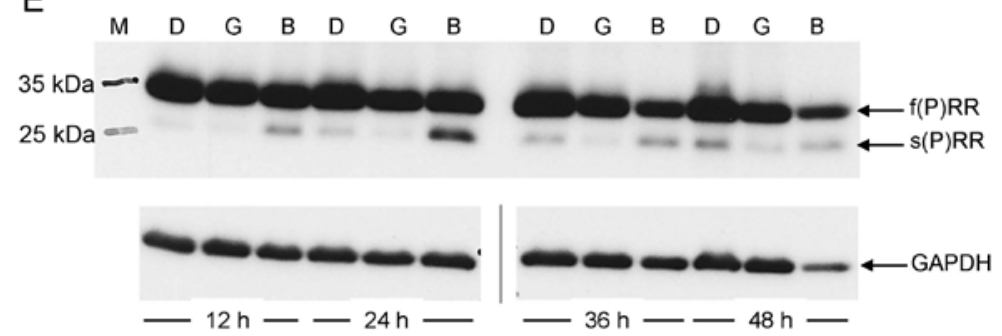

$\mathrm{s}(\mathrm{P}) \mathrm{RR} / \mathrm{GAPDH}[\%]$ (total lysates)

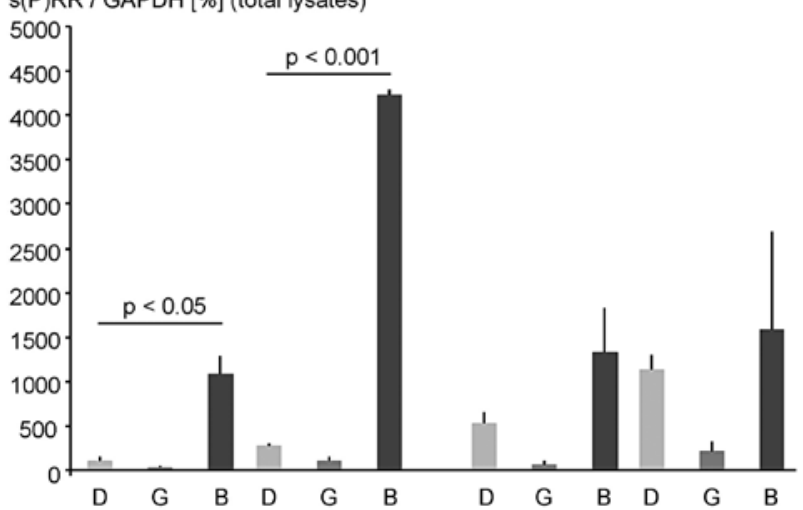

$\mathrm{F}$
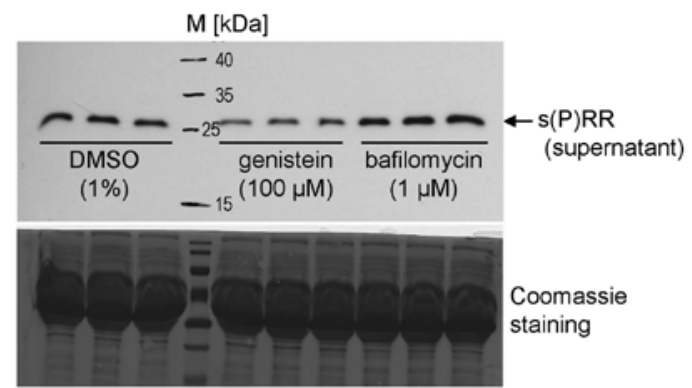

s(P)RR [\%] (supernatant)

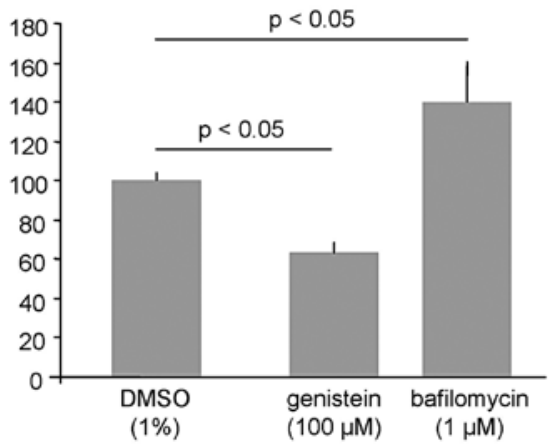

Figure 2. Continued. (E) Double-stably transfected HeLa cells were treated with genistein (100 nM; G) or bafilomycin (1 $\mu \mathrm{M}$; B) for the indicated time periods followed by Western blotting of the cellular lysates. $\mathrm{f}(\mathrm{P}) \mathrm{RR}$, full-lengh $(\mathrm{P}) \mathrm{RR}$; $\mathrm{s}(\mathrm{P}) \mathrm{RR}$, soluble (P)RR. (Lower panel) Densitometric analysis of $\mathrm{s}(\mathrm{P}) \mathrm{RR}$ [mean \pm standard deviation of the technical duplicates (one of these shown in the upper panel)] with the ordinate standardised to the GAPDH and normalised to the DMSO control (D) at each point of time is shown. (F) Double-stably transfected HeLa cells were treated with genistein or bafilomycin for $48 \mathrm{~h}$ before harvest and concentration of the cellular supernatant followed by anti-(P)RR Western blotting. Coomassie staining served as loading control for supernatant proteins. (Lower panel) Densitometric analysis (mean \pm standard deviation of technical triplicates) of $s(\mathrm{P}) \mathrm{RR}$ in supernatant is shown. M, molecular weight marker.

Effects of glucose, genistein and bafilomycin on PLZF translocation. Finally, we aimed to ascertain whether genistein and bafilomycin affect the nuclear translocation of PLZF at different glucose concentrations. Genistein $(100 \mu \mathrm{M})$ (Fig. 6A) and bafilomycin $(1 \mu \mathrm{M})$ (Fig. 6B) reduced the nuclear content of PLZF under physiological and high glucose conditions after $18 \mathrm{~h}$ in the HEK293T cells. This effect of genistein was not observed after $12 \mathrm{~h}$ in the HEK293T and KELLY cells (data not shown). Glucose concentration per se (i.e., under DMSO) appeared not to alter the PLZF content (Fig. 6).

Cellular effects of the $(P) R R$ sub-pathways. Regarding cellular effects of the (pro)renin-(P)RR-PLZF cascade, HEK cells stably overexpressing prorenin were analysed regarding proliferation using a BrdU assay (Fig. 7A). Compared to the non-overexpressing control cells, prorenin caused an increase in proliferation. This pro-proliferative effect was attenuated by siRNA against (P)RR, siRNA against PLZF and by pharmacological interventions using genistein or bafilomycin.

In addition, we examined the (pro)renin-independent cellular effects of the (P)RR. Repression of (P)RR expression by siRNA in wild-type neuronal cells in a system without (pro)renin supplementation significantly decreased cell number (Fig. 7B), whereas PLZF knockdown by siRNA had no effect (data not shown). Finally, the dose-dependent proliferative effects of genistein and bafilomycin were analysed in wild-type KELLY cells (Fig. 7C). Bafilomycin strongly decreased proliferation in contrast to genistein in a cellular system without incubation of recombinant or purified (pro)renin.

To analyse whether the altered proliferation is translated into different cell numbers, we performed XTT and ATP assay in addition to total protein measurements under the cell culture conditions as in Fig. 7B and $\mathrm{C}$ since these assays are indicative of total cell count (Fig. 7D). The shapes of the dose-response curves including the rightward shift between genistein and bafilomycin were observed in all of the assays and in the different cell types indicating that bafilomycin reduced the cell number through inhibition of proliferation. Furthermore, a minor contribution of direct cytotoxicity to the cell numberreducing effects of bafilomycin A1 was demonstrated using a LDH assay (Fig. 7D).

Finally, we examined whether small molecule interventions using genistein or bafilomycin and gene silencing approaches using siRNA exhibit similar effects. Affecting the (P)RR by either bafilomycin or siRNA, in the absence of (pro)renin, both strongly reduced cell number in a concentration-response relationship (Fig. 8). In contrast, affecting PLZF by either exposure to genistein or siRNA, in the absence of prorenin, did not alter the cell number with the exception of $100 \mu \mathrm{M}$ genistein (Fig. 8).

Concerning the intracellular phenotypic impacts of genistein and bafilomycin, we determined intravesicular $\mathrm{pH}$ regulation using Lysotracker fluorescence dye in HeLa cells. To exclude effects on cell number, incubation of these substances was restricted to 2 h. Fig. 9 indicates that bafilomycin increased 

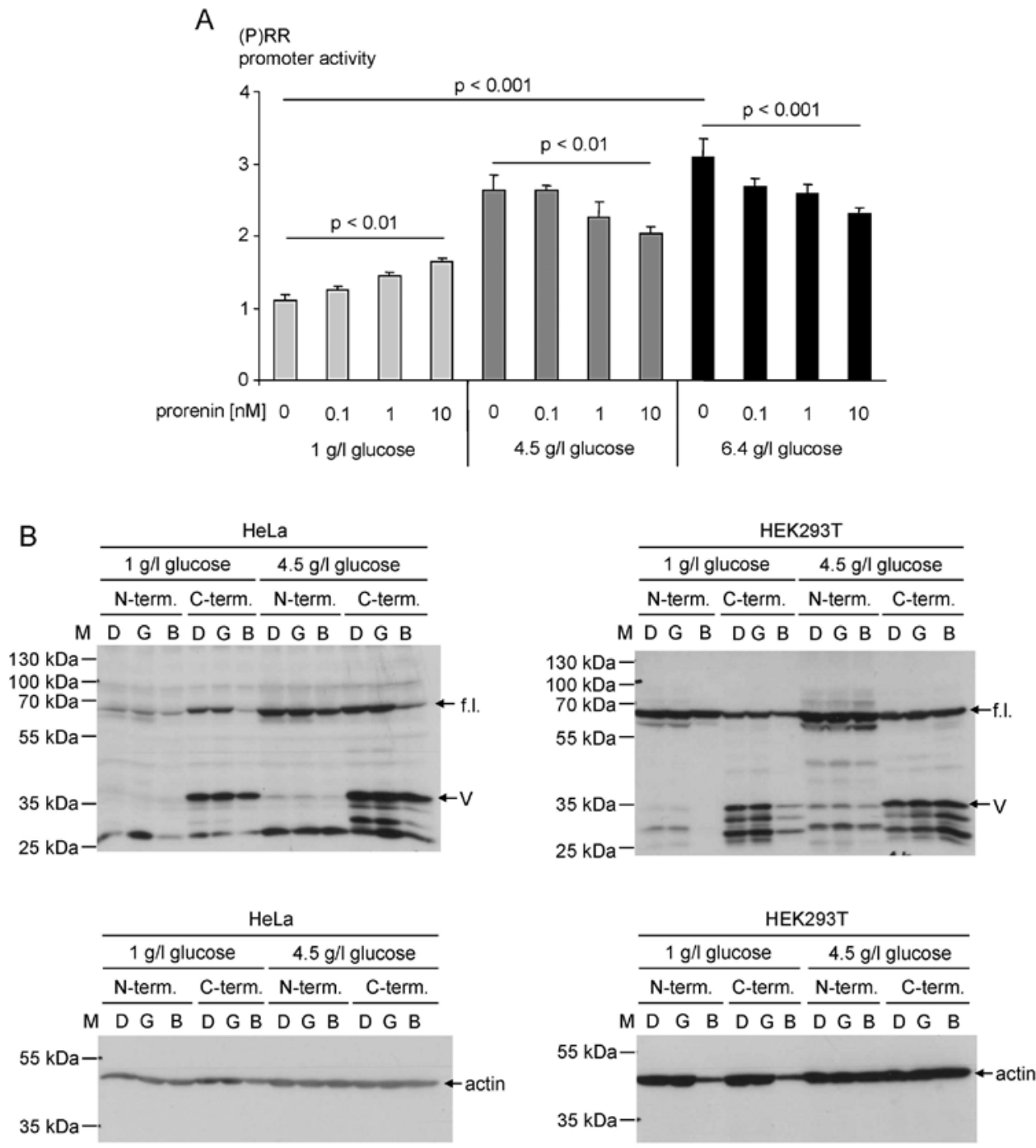

Figure 3. Effects of high glucose conditions on (pro)renin receptor $[(\mathrm{P}) \mathrm{RR}]$ promoter activity and (P)RR isoform expresssion. (A) HeLa cells double-stably transfected with (P)RR promoter luciferase constructs were stimulated, after $24 \mathrm{~h}$ of starving, with prorenin for $24 \mathrm{~h}$ under different glucose concentrations ( $\mathrm{n}=3$ for each intervention). (B) HeLa and HEK293T wild-type cells, cultured under the indicated conditions, were transiently transfected with an expression vector encoding full-length RER C- or N-terminally fused with an EGFP-tag of $26 \mathrm{kDa}$ (pEGFP-N1 or pEGFP-C3, respectively). (P)RR isoforms generated endogenously by post-translational processing were detected by Western blotting of total cellular proteins using an anti-GFP antibody. Anti-actin Western blotting served as loading control. M, molecular weight marker; D, 1\% DMSO; G, $10 \mu \mathrm{M}$ genistein; B, $0.1 \mu \mathrm{M}$ bafilomycin; f.l., full-length (P)RR-GFP; V, V-ATPase domain of (P)RR fused to GFP.

lysosomal/peroxisomal $\mathrm{pH}$ with an $\mathrm{EC}_{50}$ of $\sim 2 \mathrm{nM}$ whereas genistein had no effect.

\section{Discussion}

There are three major findings of this study regarding the (P)RR signal transduction cascade. First, ligand glycosylation is a crucial determinant of intrinsic activity. Second, glucose concentration affects $(\mathrm{P}) \mathrm{RR}$ signalling at different levels. Third, the (P)RR exhibits constitutive, PLZF-independet proproliferative effects.

In the present study, we demonstrated that the steady-state glucose concentration does not affect the glycosylation pattern of prorenin (Fig. 4), in contrast to HbAlc glycation (i.e., nonenzymatic glycosylation) by glucose (39). The glycosylation pattern itself is crucial for the ligand activity of prorenin since deglycosylation abolishes the effect of prorenin on the
(P)RR signal transduction (Fig. 5). Furthermore, a mixture of fully deglycosylated and partially deglycosylated (i.e., one of the two glycosylation sites was completely deglycosylated) prorenin is sufficient to mediate half-maximal intrinsic activity (Fig. 5B). To the best of our knowledge, this is the first report demontrating that the intrinsic activity of prorenin depends on its glycosylation.

In contrast to the glucose-independent ligand glycosylation, high glucose conditions increased the basal (i.e., without prorenin stimulation) (P)RR activity as measured by promoter assay, and reversed the ability of prorenin regarding $(\mathrm{P}) \mathrm{RR}$ activation (Fig. 3A). This increased basal (P)RR receptor activity under high glucose was likely caused by an increased receptor expression based on the observation that glucose induced (P)RR at the protein level in HeLa cells (Fig. 3B). The increased full-length (P)RR protein expression appeared not to alter the (P)RR isoform ratio in HeLa cells (Fig. 3B). 


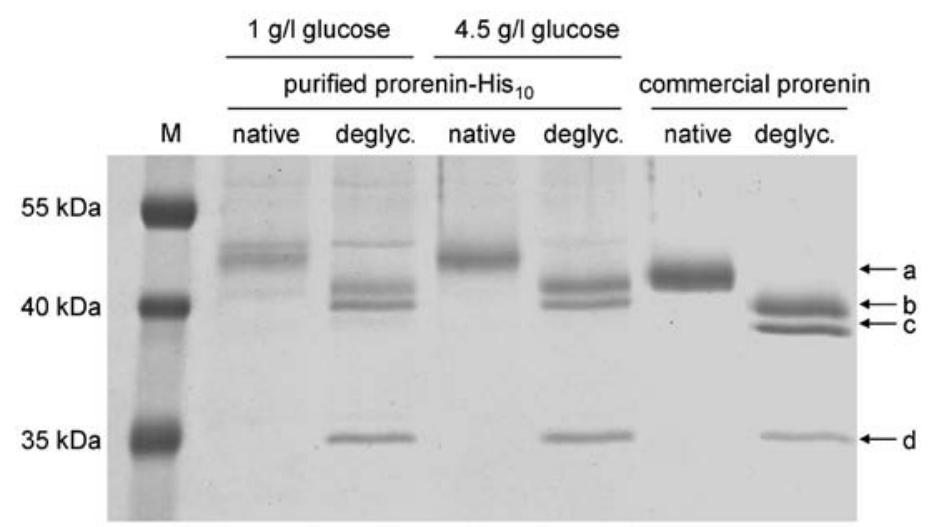

Figure 4. Effects of high glucose conditions on prorenin glycosylation. Prorenin purified from the supernatant of stably transfected Flp-In-293-HEK cells and a commercially obtained prorenin were deglycosylated (deglyc.) and resolved via sodium dodecyl sulfate-polyacrylamide gel electrophoresis (SDS-PAGE) followed by Coomassie staining. 'Native' indicates a mock incubation without glycosidase. M, molecular weight marker; a, completely glycosylated native or His-tagged prorenin; b, prorenin deglycosylated at one asparagine; c, prorenin deglycosylated at both asparagines; d, N-glycosidase $\mathrm{F}$ itself.

A
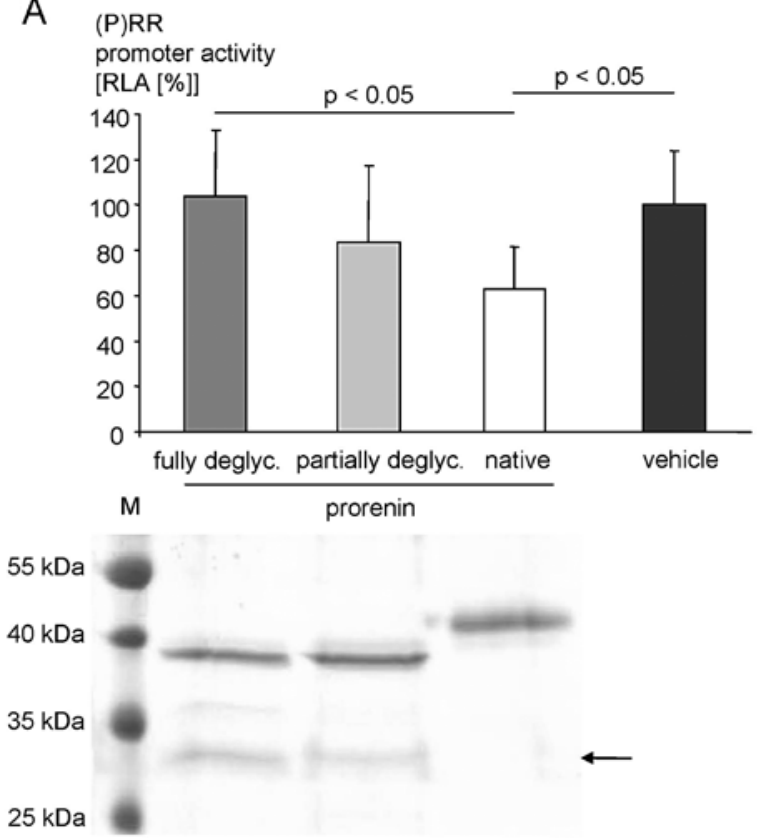

B

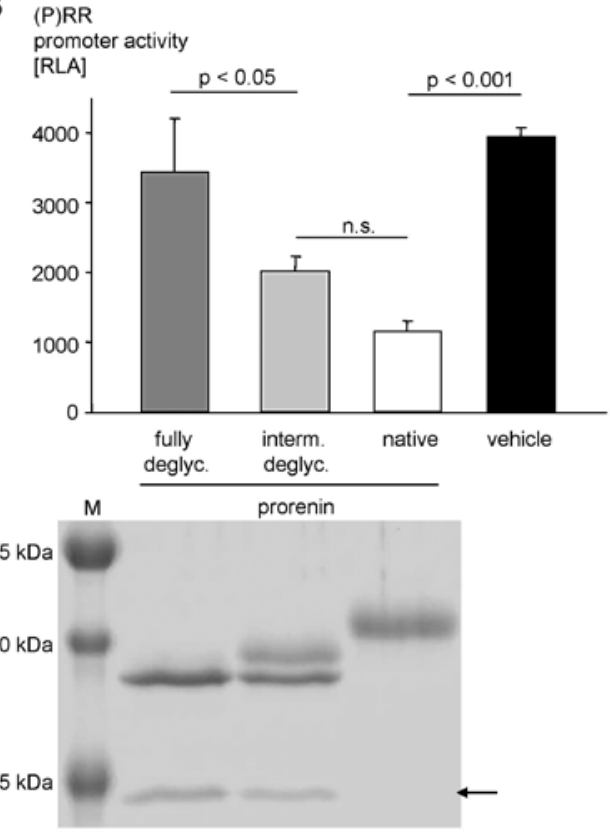

Figure 5. Deglycosylation of prorenin reduces its intrinsic activity. (A) Wild-type HeLa cells were transiently transfected with the (pro)renin receptor [(P)RR] promoter construct [-1; -1100]/pGL4.14 encoding firefly luciferase. Cotransfection of the phRL-null plasmid encoding humanised Renilla luciferase served for standardisation. Twenty-four hours after transfection, cells were starved for $24 \mathrm{~h}$ followed by stimulation with native or differently deglycosylated (deglyc.) prorenin (10 nM each; recombinant His $_{10}$-tagged prorenin from Flp-In-HEK293 cells) for another $24 \mathrm{~h}$. Relative luciferase activity (RLA) served as readout. Data are based on three independent experiments (each $n=3$ ) and normalised to the vehicle group. (Lower panel) Coomassie-stained sodium dodecyl sulfate-polyacrylamide gel electrophoresis (SDS-PAGE) of native and differently deglycosylated prorenins used. The arrow indicates the $\mathrm{N}$-glycosidase $\mathrm{F}$ itself. (B) Wild-type KELLY cells cultivated in $2 \mathrm{~g} / 1$ glucose were transiently transfected with the (P)RR promoter construct [-1; -1100]/pGL4.14 encoding firefly luciferase $(\mathrm{n}=3)$. Cotransfection of the Renilla-encoding phRL-null plasmid served for standardisation. Twenty-four hours after transfection, cells were starved for $24 \mathrm{~h}$ followed by stimulation with native commercial $(10 \mathrm{nM})$ or differently deglycosylated commercial prorenin $(10 \mathrm{nM}$ each) for another $24 \mathrm{~h}$. n.s., non-significant. (Lower panel) Coomassie-stained SDS-PAGE of native and differently deglycosylated prorenins used. Intermediate (interm) deglyc.denotes the mixture of completely deglycosylated and partially deglycosylated prorenin molecules. The arrow indicates the N-glycosidase F itself.

The strong upregulation of full-length (P)RR protein expression in HeLa cells cultivated in high glucose conditions observed in this study is consistent with previous studies which demonstrated an upregulation of (P)RR mRNA and protein in hearts (21) as well as kidneys (22) of diabetic rats, of (P)RR protein in kidneys of patients with diabetic nephropathy (40), and of (P)RR mRNA and protein in rat mesangial cells by glucose (41). Mechanistically, NF- $\mathrm{B}, \mathrm{AP}-1$ and Sp1/Sp3 appear to be involved in the (P)RR promoter regulation by high glucose (42). The authors showed that an exchange of c-jun, c-fos, NF- $\kappa \mathrm{B}$ p 65 and NF- $\kappa \mathrm{B}$ p50 on cis-elements of the $(\mathrm{P}) \mathrm{RR}$ promoter mediated the glucose responsiveness of this gene, indicating a complex promoter regulation in which more than one transcription factor was involved. Furthermore, dissocation of V-ATPase subunits was found to be promoted by low glucose levels (43) which in turn may affect the regulation 
A

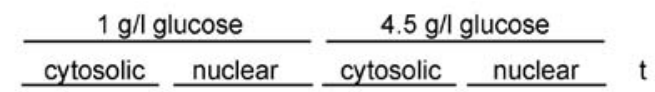

M D G1 G2 D G1 G2 D G1 G2 D G1 G2
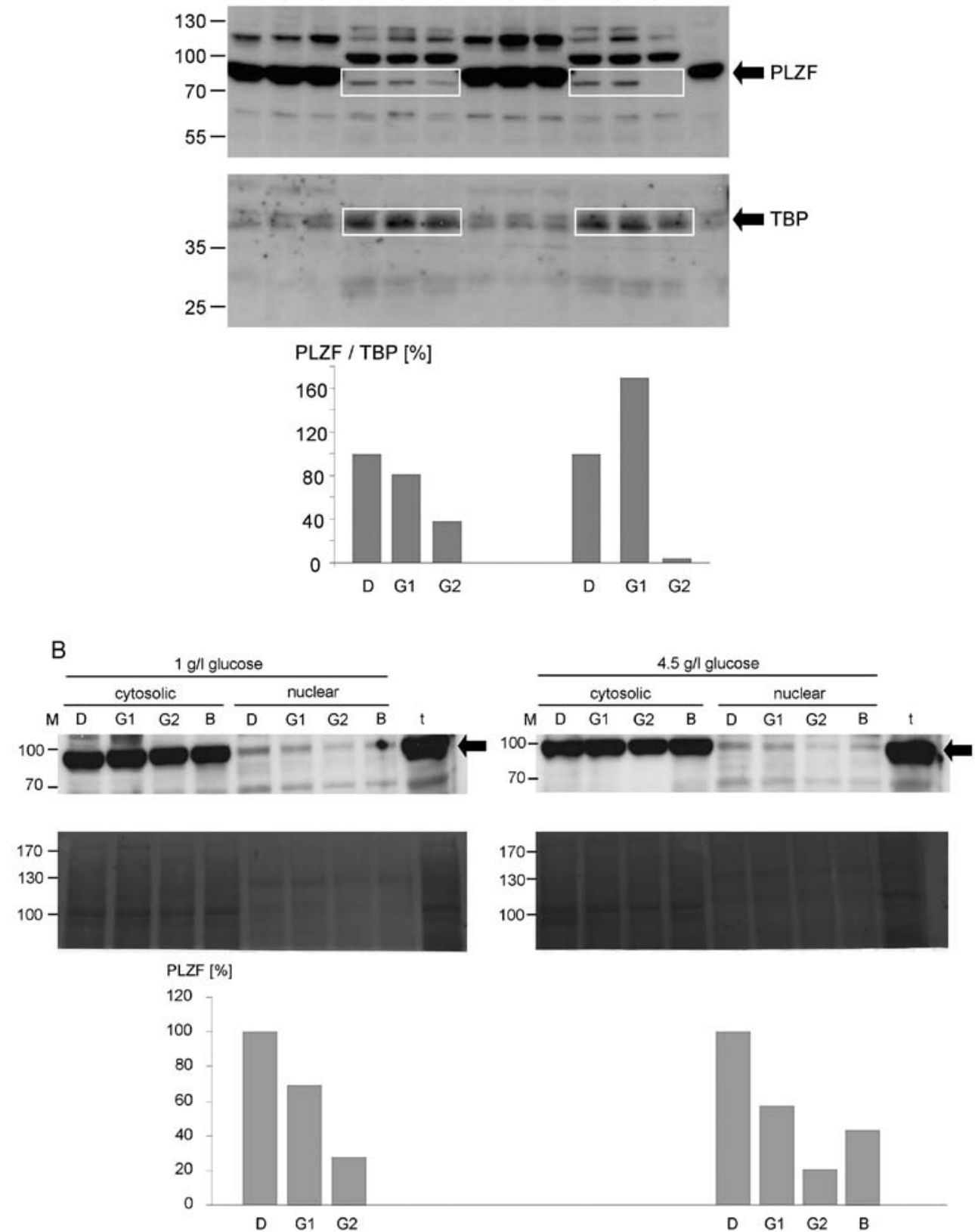

Figure 6. Genistein and bafilomycin affect nuclear promyelocytic leukemia zinc finger protein (PLZF) content. (A) HEK293T wild-type cells cultured under the indicated glucose concentrations were treated with $0.1 \% \mathrm{DMSO}$ (D), $10 \mu \mathrm{M}$ genistein (G1) or $100 \mu \mathrm{M}$ genistein (G2) for $18 \mathrm{~h}$ before cell harvest for fractionated protein extraction. Total protein lysate (lane t) of HEK293T cells served as the positive control. Western blotting was performed using the anti-PLZF antibody and an anti-TBP antibody for standardisation. (Lower panel) Densitometric analysis of the nuclear protein fractions (as indicated by white rectangles in the western blot) is presented. According to the literature, the molecular weight of PLZF (arrow) is between 66 and $97 \mathrm{kDa}$ (77). M, molecular weight marker in $\mathrm{kDa}$. (B) Independent experiment as in (A) also including incubation with $1 \mu \mathrm{M}$ bafilomycin (B) for $18 \mathrm{~h}$ before harvest. Coomassie staining (middle panel) served as the loading control.

of the (P)RR gene, since it encodes an essential accessory protein of V-ATPases (44).

Focusing on the regulatory levels, bafilomycin and genistein increased $(\mathrm{P}) \mathrm{RR}$ promoter activity and $(\mathrm{P}) \mathrm{RR}$ mRNA (Fig. 2A-D). Bafilomycin but not genistein decreased exogenous (i.e., under control of a CMV promoter) full-length (P)RR protein in HeLa cells (Fig. 3B). Concerning endogenous (P)RR, soluble (P)RR was strongly increased by bafilomycin in the total lysates and in the supernatant (Fig. 2E and F). This clearly increased $\mathrm{s}(\mathrm{P}) \mathrm{RR}$ expression may be reflected by an increased translation of full-length (P)RR followed by direct processing into the soluble isoform and a rapid degradation of the V-ATPase-associated isoform. This would also explain why the full-length (P)RR protein expression was almost unaltered by bafilomycin (Fig. 2E) and is consistent with a recent conclusion by Fukushima et al, that the elevation of plasma 
A

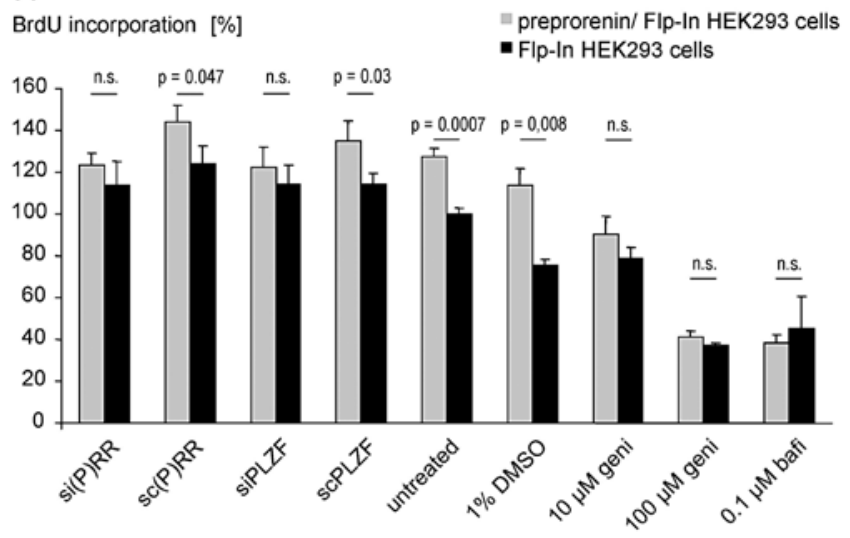

B
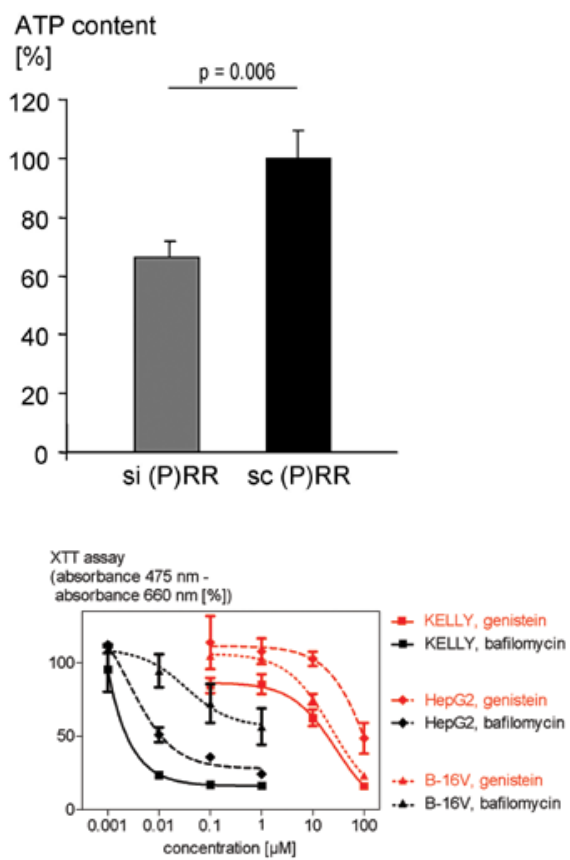

total protein concentration
$[\%]$

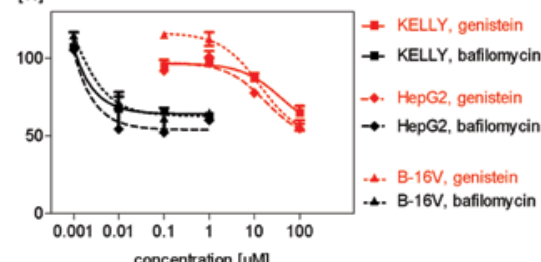

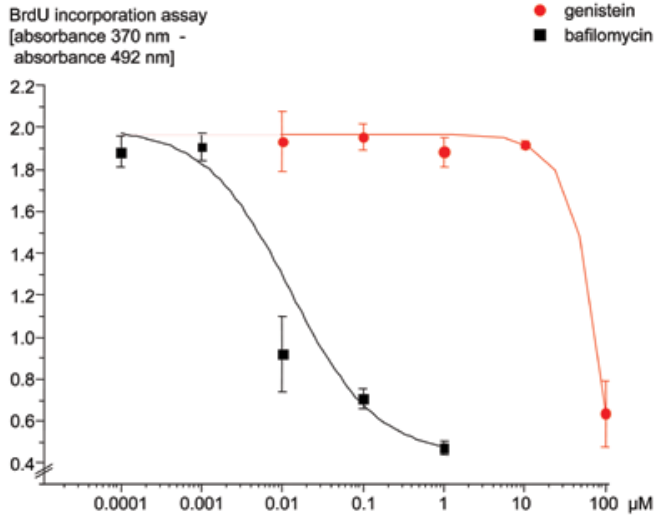
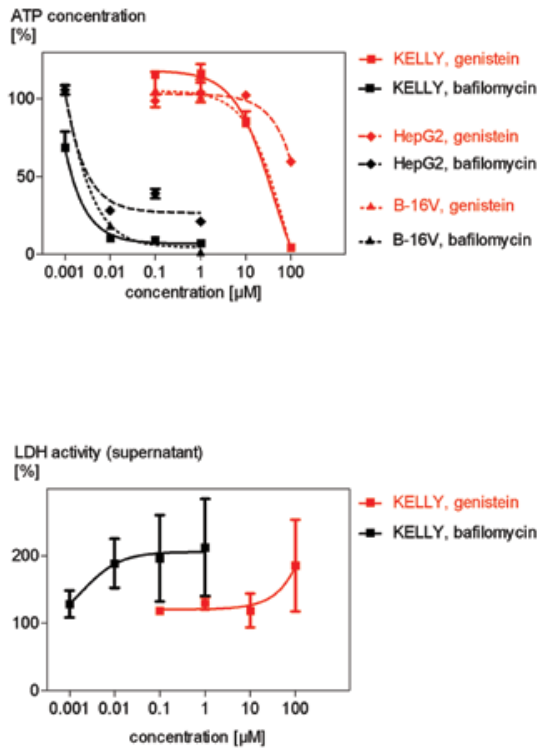

Figure 7. Cellular effects of the (pro)renin receptor [(P)RR] pathway. (A) The pro-proliferative effects of prorenin are mediated by (P)RR and promyelocytic leukemia zinc finger protein (PLZF). Flp-In HEK293 cells (cultured in $1 \mathrm{~g} / 1$ glcuose) stably overexpressing prorenin or respective control cells were treated with siRNA against (P)RR [si(P)RR] or PLZF (siPLZF), respective scrambled control siRNAs (sc), genistein (geni) or bafilomycin A1 (bafi) for $48 \mathrm{~h}$ before harvest $(n=3)$. Untreated (without transfection and without DMSO) Flp-In cells were set to 100\%. n.s., non-significant. (B) Constitutive pro-proliferative effects of (P)RR in wild-type KELLY cells. Cell number was quantified in KELLY wild-type cells ( $2 \mathrm{~g} / \mathrm{l}$ glucose) using an ATP-based assay ( $\mathrm{n}=3$ ) $48 \mathrm{~h}$ after transfection of siRNA against (P)RR [si(P)RR]. Scrambled siRNA [sc(P)RR] served as control. (C) Effects of genistein and bafilomycin on the proliferation in KELLY cells. KELLY wild-type cells ( $2 \mathrm{~g} / 1$ glucose) were incubated with genistein or bafilomycin A1 for $48 \mathrm{~h}$ before harvest. The abscissa indicates the concentration. Proliferation was determined by BrdU incorporation assay ( $\mathrm{n}=3$ ). (D) Effects of genistein and bafilomycin on cell number in KELLY, HepG2 and B-16V cells and on the cytotoxic effect on KELLY cells. The indicated cell lines ( $2 \mathrm{~g} / 1$ glucose) were incubated with genistein or bafilomycin A1 for $48 \mathrm{~h}$ Mitochondrial dehydrogenase activity, an indicator of the number of metabolic active cell, was quantified by XTT assay in triplicates. Total cellular protein $(\mathrm{n}=3)$ and cellular ATP concentration $(\mathrm{n}=3)$ were measured using the Bradford assay and the Celltiter-Glo assay. Lactate dehydrogenase $(\mathrm{LDH})$ activity in the supernatant was determined as a measure of cytotoxicity; $1 \%$ Triton X-100 served as a positive control (i.e., full kill) yielding an LDH activity of $\sim 700 \%$ in KELLY cells. LDH data represent the mean of four independent experiments (each $\mathrm{n}=3$ ). DMSO ( $1 \%$ final) was set to $100 \%$ in every experiment. Data values represented by the various symbols in all assays are the mean of triplicates \pm standard deviation. Lines in all diagrams represent sigmoidal regression calculates as described in Materials and methods. 


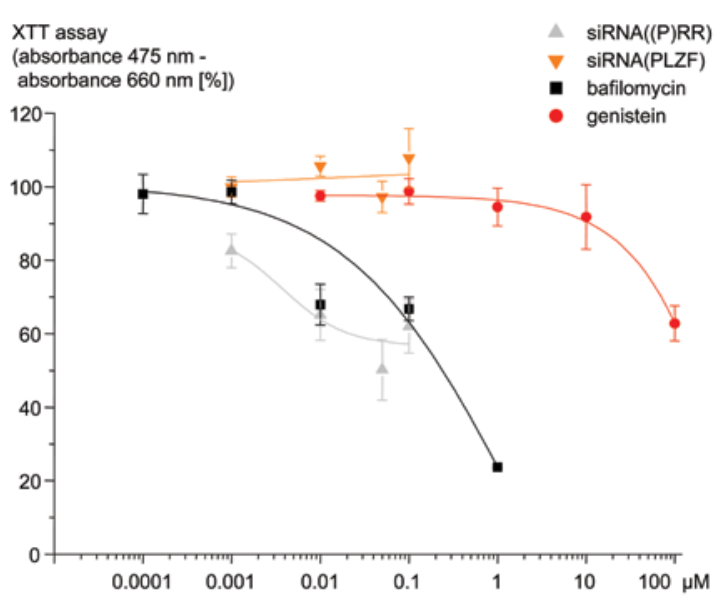

Figure 8. Correlation of small molecule and siRNA effects regarding cell number. HeLa cells double-stably transfected with the (pro)renin receptor $[(\mathrm{P}) \mathrm{RR}]$ reporter constructs $(4.5 \mathrm{~g} / 1$ glucose $)$ were incubated with different concentrations of genistein and bafilomycin for $48 \mathrm{~h}$. In addition, siRNA against (P)RR or promyelocytic leukemia zinc finger protein (PLZF) was applied once for $48 \mathrm{~h}$ at the indicated concentrations: 1, 10,50 and $100 \mathrm{nM}$, respectively. The number of viable cells were determined by XTT assay. The data for the small molecule and siRNA interventions were standardised to DMSO or scrambled siRNA, respectively, i.e., a value of 100 on the ordinate indicates an effect size that equals $1 \%$ DMSO or scrambled siRNA. Al measurements are triplicates, and the error bars denote standard deviation.

$\mathrm{s}(\mathrm{P}) \mathrm{RR}$ level may indicate an upregulation of the full-length form (45).

Here, we were able to confirm the previous data of our group $(23,24)$ that revealed that prorenin mediates proproliferative effects via the (P)RR-PLZF axis (Fig. 7A) which is also consistent with a microarray analysis linking (pro)renin stimulation with a gene signature associated with cardiac hypertrophy (20). Furthermore, research indicates that (pro) renin increases DNA synthesis (46) and proliferation (47) of vascular smooth muscle cells, and that prorenin can increase protein and DNA synthesis in cardiomyocytes underlying myocyte hypertrophy and proliferation (48). In addition, it was found that prorenin increased the proliferation of endothelial cells and that melanoma xenografts stably transfected with prorenin had an increased tumour growth in vivo compared to mock controls likely involving the (P)RR since an angiotensin AT1 receptor blocker was ineffective in vitro (49).

Our data obtained in neuronal, melanoma, hepatoma and epithelial cells in the absence of stimulation with the ligand (pro)renin indicate that the (P)RR exerts additional constitutive, cell type-independent pro-proliferative/pro-survival effects (Fig. 7C and D). These effects are independent of PLZF as indicated by our experiments using siRNA against PLZF or genistein. This is in contrast to the essential role of PLZF in (pro)renin-induced pro-proliferation as discussed above (Fig. 10). This constitutive function of the (P)RR is consistent with the phenotype of the cardiomyocyte-specific (P)RR knockout which is characterised by cardiac cell death (50) and also with the phenotype of the podocyte-specific (P)RR knockout which is characterised by non-apoptotic podocyte cell death (51) since both phenotypes can be explained by a V-ATPase dysfunction. Moreover, repression of

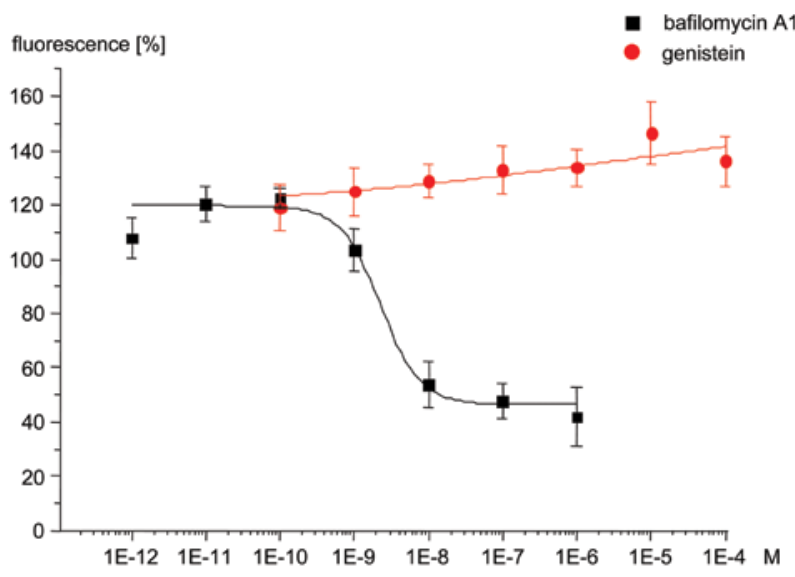

Figure 9. Differential effects of bafilomycin and genistein on lysosomal/ peroxisomal $\mathrm{pH}$. HeLa wild-type cells (4.5 g/l glucose) were incubated with the indicated concentrations of bafilomycin A1 or genistein for $2 \mathrm{~h}$ before Lysotracker fluorescence emission was measured $(n=6 /$ concentration of each compound). Indicated concentrations are defined as follows: $1 \mathrm{E}-12 \mathrm{M}=10^{-12} \mathrm{M}$ and so forth

(P)RR expression by siRNA reduced the viability of cultured cardiomyoblasts in an experimental setting without (pro)renin incubation (21). The role of the constitutive (P)RR function in cellular survival is also supported by the central nervous system necrosis observed in zebrafish with (P)RR gene mutagenesis (52) but also in zebrafish with genetic alterations in different V-ATPase subunits (30). Furthermore, the ligand renin is only expressed in mammalian and nonmammalian vertebrates (53) but not in invertebrates such as C. elegans, which is not viable when (P)RR is lacking (27). The importance of the constitutive activity is further supported by the fact that at least plasma (pro)renin levels and, therefore, even more (pro)renin concentrations in cell culture medium with a serum content of $10 \%$, are too low to be of biological relevance with respect to (P)RR activation (54).

The extent to which (pro)renin-independent effects are mediated by the Wnt pathway, considering the essential role of the (P)RR in its signalling (26), and/or by the V-ATPase isoform remains to be elucidated. Consistent with a role of Wnt in the basal (i.e., ligand-independent) effects of the (P)RR observed here, it was shown that (P)RR function within the Wnt pathway is renin-independent (26).

The overall (i.e., ligand-dependent and/or ligand-independent) role of the (P)RR in cellular survival is also illustrated by the observation that embryonic stem (ES) cells deficient in the (P)RR gene are incompatible with the development of chimeric mice when injected into blastocysts $(51,55)$ and by the likely involvement of the (P)RR in the growth of glioma cells (56).

The present study is the first to simultaneously address the effects of the small molecules genistein and baflomycin. Genistein is a phytoestrogen known to interact with estrogen receptors $\alpha(E R \alpha)$ and $E R \beta$ leading to activation of ER responsive genes $(57,58)$. Furthermore, genistein can inhibit tyrosine kinases (59) and aspects of Wnt signalling (60) in addition to its effects on histone modifications and DNA methylation (i.e., epigenetic modulations) (61) as well as on NF- $\mathrm{kB}(62)$ and Smad (63) signal transductions. In the context of our data, it is 


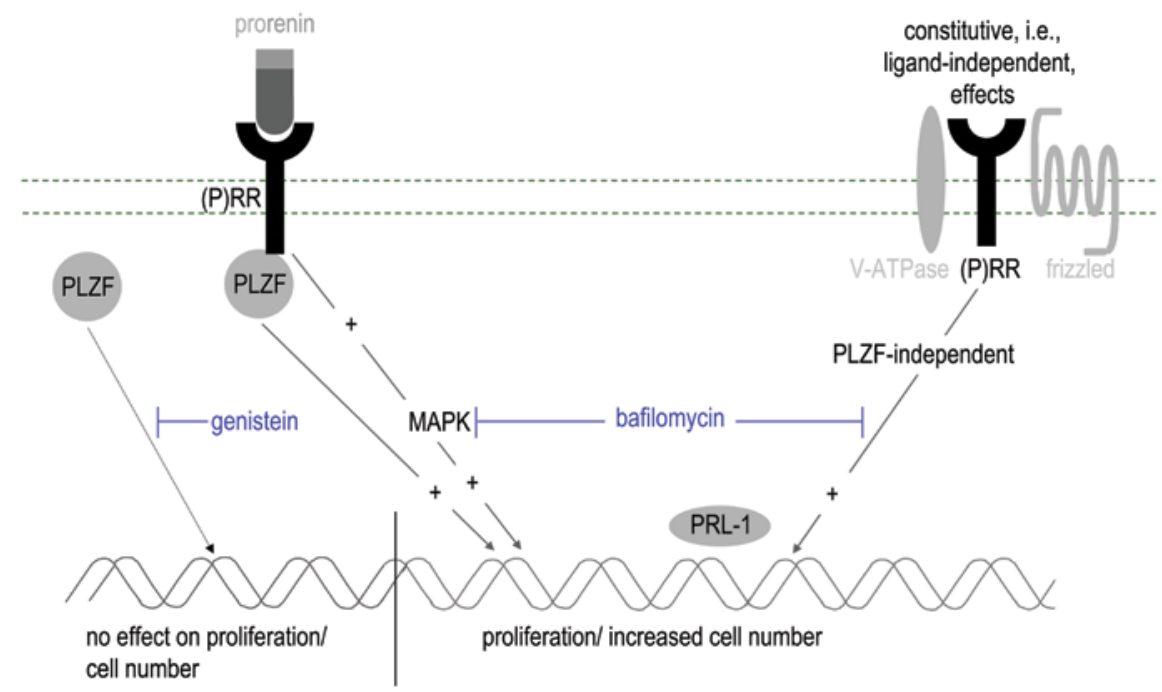

Figure 10. The prorenin receptor [(P)RR] mediates constitutive promyelocytic leukemia zinc finger protein (PLZF)-independent as well as prorenin-mediated PLZF-dependent pro-proliferative effects. The pro-proliferative effect of the prorenin-(P)RR-PLZF axis was previously demonstrated by our group (24) whereas the constitutive functions of the (P)RR were analysed in the present study. MAPKs (78), the Wnt pathway (79) and V-ATPases (80) are known to mediate proliferation in general and likely contribute to pro-survival/pro-proliferative effects of the (P)RR $(21,51,81,82)$. In addition, the phosphatase PRL-1 may be involved in the regulation of proliferation downstream of the (P)RR (1). The inhibitory effects of bafilomycin on the prorenin-induced activation of MAPKs have been shown by Advani et al (29). Genistein inhibits basal (data obtained in this study) and angiotensin II-induced (33) nuclear translocation of PLZF.

important to note that genistein inhibits the nuclear translocation of PLZF (33). We also observed that genistein inhibited nuclear translocation of PLZF in HEK293T cells indicating the contribution of this genistein-mediated mechanism in our experiments. Since HeLa-S3 cells do not express ER $\alpha$ and ER $\beta$ receptors (data not shown) the effects of genistein on this cell type are non-ER-mediated. Similar to our data that genistein does not significantly inhibit cell growth, the MTT assaydetermined $\mathrm{IC}_{50}$ value of genistein in a panel of cancer cell lines was in the two-digit micromolar range (64). Consistently, a recent clinical phase II trial indicated that genistein did not increase the survival of pancreatic cancer patients (65).

Bafilomycin A1 is a specific V-ATPase inhibitor which can inhibit the ligand- (i.e., prorenin- and renin-)dependent (29) and Wnt-associated (26) signal transduction of the (P)RR.

In accordance with our data, bafilomycin A1 was found to decrease the growth of different tumour cell lines in vitro, with an $\mathrm{IC}_{50}$ of $5 \mathrm{nM}$ regarding cellular viability of pancreatic cancer cells (68), as well as xenograft growth in vivo (66-68). Nevertheless, its toxicity excludes its use in clinical trials $(69,70)$.

Concerning cardiovascular indications, it was recently demonstrated that genistein reduced proteinuria, albuminuria and glomerular deposits in streptozotocin-induced diabetic mice (71), similar effects as observed with the anti-prorenin decoy peptides discussed above (3). In addition to these beneficial effects, genistein was found to protect pancreatic $\beta$ cells from high glucose-induced apoptosis (72). In contrast, bafilomycin A1 reduced pancreatic islet size and impaired glucose tolerance in animal models $(73,74)$ hypothetically linking this bacterial toxin to the development of type I diabetes (75).

Based on our data, we conclude that genistein is a small molecular mimetic of siRNA against PLZF, whereas bafilomycin exerted similar effects as siRNA against (P)RR for the following reasons. First, genistein, bafilomycin as well as siRNAs against PLZF or (P)RR all increased (P)RR promoter activity (Figs. 1 and 2B). Secondly, neither PLZF silencing by siRNA nor genistein exerted significant effects on cell number (Fig. 8). In all our cellular phenotypic assays regarding total protein concentration, cell number and proliferation, genistein had no effects except at the highest $(100 \mu \mathrm{M})$ concentration used (Fig. 7C and D). Since this concentration is far beyond the $\mathrm{EC}_{50}$ (Fig. 2B), this indicates putative unspecific effects at $100 \mu \mathrm{M}$, which is consistent with the threshold of $5 \mu \mathrm{M}$ genistein regarding a non-physiological in vitro concentration (76). In contrast, both siRNA against (P)RR and also bafilomycin similarly reduced cell number (Fig. 8). Third, other groups have shown that wild-type podocytes treated with bafilomycin A1 are characterised by similar morphologic and $\mathrm{pH}$ changes compared to podocytes with (P)RR deletion (51).

We further conclude that (P)RR and PLZF functions are not identical, despite a similar impact on promoter feedback (Fig. 1) and a similar effect on prorenin-induced proliferation (24), for the following reasons. First, as discussed above, (P)RR affected cell number/proliferation in contrast to PLZF. Second, genistein and bafilomycin had distinct effects on (P)RR isoform expression (Fig. 3B). Third, bafilomycin, as expected, increased lysosomal/peroxisomal $\mathrm{pH}$ as indicated by a reduction in Lysotracker fluorescence emission in contrast to genistein (Fig. 9).

To conclude, our data indicate that the $(\mathrm{P}) \mathrm{RR}$ does not only exert angiotensin II-independent $(2,23)$ but also (pro)renin-independent (i.e., constitutive) effects. By employing dose-response analyses and various cellular assays, the present study is the first detailed description of the constitutive, pro-proliferative/prosurvial actions of this receptor. Furthermore, the novel finding that glycosylation of prorenin is crucial regarding its ability to initiate a signal transduction at the (P)RR was demonstrated. 


\section{Acknowledgements}

The study was supported by grants from the BMBF (GO-Bio programme, no. 0315092 and VIP-programme, no. 0275 03V0367), the Investitionsbank Berlin (IBB) [ProFIT programme, no. 10138510; Europäischer Fonds für regionale Entwicklung (EFRE) of the European Union (EU)] and by the Stiftung Charité.

\section{References}

1. Funke-Kaiser H, Zollmann FS, Schefe JH and Unger T: Signal transduction of the (pro)renin receptor as a novel therapeutic target for preventing end-organ damage. Hypertens Res 33: 98-104, 2010.

2. Nguyen G, Delarue F, Burckle C, Bouzhir L, Giller T and Sraer JD: Pivotal role of the renin/prorenin receptor in angiotensin II production and cellular responses to renin. J Clin Invest 109: 1417-1427, 2002.

3. Ichihara A, Hayashi M, Kaneshiro Y, et al: Inhibition of diabetic nephropathy by a decoy peptide corresponding to the 'handle' region for nonproteolytic activation of prorenin. J Clin Invest 114: 1128-1135, 2004.

4. Ichihara A, Kaneshiro Y, Takemitsu T, et al: Nonproteolytic activation of prorenin contributes to development of cardiac fibrosis in genetic hypertension. Hypertension 47: 894-900, 2006.

5. Kaneshiro Y, Ichihara A, Sakoda M, et al: Slowly progressive, angiotensin II-independent glomerulosclerosis in human (pro) renin receptor-transgenic rats. J Am Soc Nephrol 18: 1789-1795, 2007.

6. Susic D, Zhou X, Frohlich ED, Lippton H and Knight M Cardiovascular effects of prorenin blockade in genetically spontaneously hypertensive rats on normal and high-salt diet. Am J Physiol Heart Circ Physiol 295: H1117-H1121, 2008.

7. Ichihara A, Suzuki F, Nakagawa T, et al: Prorenin receptor blockade inhibits development of glomerulosclerosis in diabetic angiotensin II type 1a receptor-deficient mice. J Am Soc Nephrol 17: 1950-1961, 2006.

8. Takahashi H, Ichihara A, Kaneshiro Y, et al: Regression of nephropathy developed in diabetes by (pro)renin receptor blockade. J Am Soc Nephrol 18: 2054-2061, 2007.

9. Muller DN, Klanke B, Feldt S, et al: (Pro)renin receptor peptide inhibitor 'handle-region' peptide does not affect hypertensive nephrosclerosis in Goldblatt rats. Hypertension 51: 676-681, 2008.

10. Feldt S, Maschke U, Dechend R, Luft FC and Muller DN: The putative (pro)renin receptor blocker HRP fails to prevent (pro) renin signaling. J Am Soc Nephrol 19: 743-748, 2008.

11. Nguyen G and Muller DN: The biology of the (pro)renin receptor. J Am Soc Nephrol 21: 18-23, 2010.

12. Ryuzaki M, Ichihara A, Ohshima Y, et al: Involvement of activated prorenin in the pathogenesis of slowly progressive nephropathy in the non-clipped kidney of two kidney, one-clip hypertension. Hypertens Res 34: 301-307, 2011.

13. Kiyomoto $\mathrm{H}$ and Moriwaki K: Chronic blockade of the (pro) renin receptor ameliorates the kidney damage in the non-clipped kidney of Goldblatt hypertension. Hypertens Res 34: 289-291, 2011.

14. Nagai Y, Ichihara A, Nakano D, et al: Possible contribution of the non-proteolytic activation of prorenin to the development of insulin resistance in fructose-fed rats. Exp Physiol 94: 1016-1023, 2009.

15. Lavoi JL: Methods of treating or preventing obesity and obesityrelated hypertension. Patentanmeldung WO 2009/143619 A1, 2009.

16. Satofuka S, Ichihara A, Nagai N, et al: Role of nonproteolytically activated prorenin in pathologic, but not physiologic, retinal neovascularization. Invest Ophthalmol Vis Sci 48: 422-429, 2007.

17. Satofuka S, Ichihara A, Nagai N, et al: (Pro)renin receptormediated signal transduction and tissue renin-angiotensin system contribute to diabetes-induced retinal inflammation. Diabetes 58: 1625-1633, 2009.

18. Wilkinson-Berka JL, Heine R, Tan G, Tikellis C, Cooper ME, Nguyen G and Miller AG: The role of the (pro)renin receptor in developing ischaemic and diabetic retina. J Renin Angiotensin Aldosterone Syst 9 (Suppl 1): S8, 2008.
19. Mahmud H, Sillje HH, Cannon MV, van Gilst WH and de Boer RA: Regulation of the (pro)renin-renin receptor in cardiac remodelling. J Cell Mol Med 16: 722-729, 2012.

20. Melnyk RA, Tam J, Boie Y, Kennedy BP and Percival MD: Renin and prorenin activate pathways implicated in organ damage in human mesangial cells independent of angiotensin II production. Am J Nephrol 30: 232-243, 2009.

21. Connelly KA, Advani A, Kim S, et al: The cardiac (pro)renin receptor is primarily expressed in myocyte transverse tubules and is increased in experimental diabetic cardiomyopathy. J Hypertens 29: 1175-1184, 2011.

22. Siragy HM and Huang J: Renal (pro)renin receptor upregulation in diabetic rats through enhanced angiotensin AT1 receptor and NADPH oxidase activity. Exp Physiol 93: 709-714, 2008.

23. Schefe JH, Menk M, Reinemund J, et al: A novel signal transduction cascade involving direct physical interaction of the renin/ prorenin receptor with the transcription factor promyelocytic zinc finger protein. Circ Res 99: 1355-1366, 2006.

24. Schefe JH, Neumann C, Goebel M, et al: Prorenin engages the (pro)renin receptor like renin and both ligand activities are unopposed by aliskiren. J Hypertens 26: 1787-1794, 2008.

25. Katz SA, Opsahl JA, Abraham PA and Gardner MJ: The relationship between renin isoelectric forms and renin glycoforms. Am J Physiol 267: R244-R252, 1994.

26. Cruciat CM, Ohkawara B, Acebron SP, et al: Requirement of prorenin receptor and vacuolar $\mathrm{H}^{+}$-ATPase-mediated acidification for Wnt signaling. Science 327: 459-463, 2010.

27. Bader M: The second life of the (pro)renin receptor. J Renin Angiotensin Aldosterone Syst 8: 205-208, 2007.

28. Ludwig J, Kerscher S, Brandt U, et al: Identification and characterization of a novel 9.2-kDa membrane sector-associated protein of vacuolar proton-ATPase from chromaffin granules. J Biol Chem 273: 10939-10947, 1998.

29. Advani A, Kelly DJ, Cox AJ, et al: The (pro)renin receptor: sitespecific and functional linkage to the vacuolar $\mathrm{H}^{+}$-ATPase in the kidney. Hypertension 54: 261-269, 2009.

30. Sihn G, Rousselle A, Vilianovitch L, Burckle C and Bader M: Physiology of the (pro)renin receptor: Wnt of change? Kidney Int 78: 246-256, 2010.

31. Cousin C, Bracquart D, Contrepas A, Corvol P, Muller L and Nguyen G: Soluble form of the (pro)renin receptor generated by intracellular cleavage by furin is secreted in plasma. Hypertension 53: 1077-1082, 2009

32. Yoshikawa A, Aizaki Y, Kusano K, et al: The (pro)renin receptor is cleaved by ADAM19 in the Golgi leading to its secretion into extracellular space. Hypertens Res 34: 599-605, 2011.

33. Senbonmatsu T, Saito T, Landon EJ, et al: A novel angiotensin II type 2 receptor signaling pathway: possible role in cardiac hypertrophy. EMBO J 22: 6471-6482, 2003.

34. Seifert R and Wenzel-Seifert K: Constitutive activity of G-proteincoupled receptors: cause of disease and common property of wild-type receptors. Naunyn Schmiedebergs Arch Pharmacol 366: 381-416, 2002.

35. Funke-Kaiser H, Reichenberger F, Köpke K, et al: Differential binding of transcription factor E2F-2 to the endothelin-converting enzyme-1b promoter affects blood pressure regulation. Hum Mol Genet 12: 423-433, 2003.

36. Seidel K, Kirsch S, Lucht K, et al: The promyelocytic leukemia zinc finger (PLZF) protein exerts neuroprotective effects in neuronal cells and is dysregulated in experimental stroke. Brain Pathol 21: 31-43, 2011.

37. Jansen EJ and Martens GJ: Novel insights into V-ATPase functioning: distinct roles for its accessory subunits ATP6AP1/Ac45 and ATP6AP2/(pro)renin receptor. Curr Protein Pept Sci 13: 124-133, 2012

38. Holzman TF, Chung CC, Edalji R, et al: Recombinant human prorenin from $\mathrm{CHO}$ cells: expression and purification. J Protein Chem 9: 663-672, 1990 .

39. Wautier JL and Schmidt AM: Protein glycation: a firm link to endothelial cell dysfunction. Circ Res 95: 233-238, 2004.

40. Takahashi K, Yamamoto H, Hirose T, et al: Expression of (pro)renin receptor in human kidneys with end-stage kidney disease due to diabetic nephropathy. Peptides 31: 1405-1408, 2010.

41. Huang J and Siragy HM: Glucose promotes the production of interleukine-1beta and cyclooxygenase-2 in mesangial cells via enhanced (Pro)renin receptor expression. Endocrinology 150: $5557-5565,2009$. 
42. Huang J and Siragy HM: Regulation of (pro)renin receptor expression by glucose-induced mitogen-activated protein kinase, nuclear factor-kappaB, and activator protein-1 signaling pathways. Endocrinology 151: 3317-3325, 2010.

43. Sennoune SR and Martinez-Zaguilan R: Vacuolar $\mathrm{H}^{+}$-ATPase signaling pathway in cancer. Curr Protein Pept Sci 13: 152-163, 2012.

44. Krop M, Lu X, Danser AH and Meima ME: The (pro)renin receptor. A decade of research: what have we learned? Pflugers Arch 465: 87-97, 2013.

45. Fukushima A, Kinugawa S, Homma T, et al: Increased plasma soluble (pro)renin receptor levels are correlated with renal dysfunction in patients with heart failure. Int J Cardiol 168 : 4313-4314, 2013.

46. Batenburg WW, Lu X, Leijten F, Maschke U, Muller DN and Danser AH: Renin- and prorenin-induced effects in rat vascular smooth muscle cells overexpressing the human (pro)renin receptor: does (pro)renin-(pro)renin receptor interaction actually occur? Hypertension 58: 1111-1119, 2011.

47. Sakoda M, Ichihara A, Kaneshiro Y, et al: (Pro)renin receptormediated activation of mitogen-activated protein kinases in human vascular smooth muscle cells. Hypertens Res 30: 1139-1146, 2007.

48. Saris JJ, van den Eijnden MM, Lamers JM, Saxena PR, Schalekamp MA and Danser AH: Prorenin-induced myocyte proliferation: no role for intracellular angiotensin II. Hypertension 39: 573-577, 2002

49. Uraoka M, Ikeda K, Nakagawa Y, et al: Prorenin induces ERK activation in endothelial cells to enhance neovascularization independently of the renin-angiotensin system. Biochem Biophys Res Commun 390: 1202-1207, 2009.

50. Kinouchi K, Ichihara A, Sano M, et al: The (pro)renin receptor/ ATP6AP2 is essential for vacuolar $\mathrm{H}^{+}$-ATPase assembly in murine cardiomyocytes. Circ Res 107: 30-34, 2010.

51. Riediger F, Quack I, Qadri F, et al: Prorenin receptor is essential for podocyte autophagy and survival. J Am Soc Nephrol 22: 2193-2202, 2011.

52. Amsterdam A, Nissen RM, Sun Z, Swindell EC, Farrington S and Hopkins N: Identification of 315 genes essential for early zebrafish development. Proc Natl Acad Sci USA 101: 12792-12797, 2004.

53. Liang P, Jones CA, Bisgrove BW, et al: Genomic characterization and expression analysis of the first nonmammalian renin genes from zebrafish and pufferfish. Physiol Genomics 16: 314-322, 2004.

54. Reudelhuber TL: The interaction between prorenin, renin and the (pro)renin receptor: time to rethink the role in hypertension. Curr Opin Nephrol Hypertens 21: 137-141, 2012.

55. Bader M: The (pro)renin receptor, (P)RR/ATP6AP2, a bifunctional protein? J Renin Angiotensin Aldosterone Syst 9 (Suppl 1) S5, 2008

56. Juillerat-Jeanneret L, Celerier J, Chapuis Bernasconi C, et al: Renin and angiotensinogen expression and functions in growth and apoptosis of human glioblastoma. Br J Cancer 90: 1059-1068, 2004.

57. Rusin A, Krawczyk Z, Grynkiewicz G, Gogler A, ZawiszaPuchalka J and Szeja W: Synthetic derivatives of genistein, their properties and possible applications. Acta Biochim Pol 57: 23-34, 2010.

58. Soucy NV, Parkinson HD, Sochaski MA and Borghoff SJ: Kinetics of genistein and its conjugated metabolites in pregnant Sprague-Dawley rats following single and repeated genistein administration. Toxicol Sci 90: 230-240, 2006.

59. Spinozzi F, Pagliacci MC, Migliorati G, et al: The natural tyrosine kinase inhibitor genistein produces cell cycle arrest and apoptosis in Jurkat T-leukemia cells. Leuk Res 18: 431-439, 1994

60. Su Y, Simmen FA, Xiao R and Simmen RC: Expression profiling of rat mammary epithelial cells reveals candidate signaling pathways in dietary protection from mammary tumors. Physiol Genomics 30: 8-16, 2007.
61. Zhang Y and Chen H: Genistein, an epigenome modifier during cancer prevention. Epigenetics 6: 888-891, 2011.

62. Gullett NP, Ruhul Amin AR, Bayraktar S, et al: Cancer prevention with natural compounds. Semin Oncol 37: 258-281, 2010.

63. Pavese JM, Farmer RL and Bergan RC: Inhibition of cancer cell invasion and metastasis by genistein. Cancer Metastasis Rev 29: 465-482, 2010.

64. Rusin A, Zawisza-Puchalka J, Kujawa K, et al: Synthetic conjugates of genistein affecting proliferation and mitosis of cancer cells. Bioorg Med Chem 19: 295-305, 2011.

65. El-Rayes BF, Philip PA, Sarkar FH, et al: A phase II study of isoflavones, erlotinib, and gemcitabine in advanced pancreatic cancer. Invest New Drugs 29: 694-699, 2011.

66. McSheehy PM, Troy H, Kelland LR, Judson IR, Leach MO and Griffiths JR: Increased tumour extracellular $\mathrm{pH}$ induced by Bafilomycin A1 inhibits tumour growth and mitosis in vivo and alters 5-fluorouracil pharmacokinetics. Eur J Cancer 39: $532-540,2003$

67. Kinoshita K, Waritani T, Noto M, et al: Bafilomycin A1 induces apoptosis in PC12 cells independently of intracellular $\mathrm{pH}$. FEBS Lett 398: 61-66, 1996.

68. Ohta T, Arakawa H, Futagami F, et al: Bafilomycin A1 induces apoptosis in the human pancreatic cancer cell line Capan-1. J Pathol 185: 324-330, 1998.

69. Lee CM and Tannock IF: Inhibition of endosomal sequestration of basic anticancer drugs: influence on cytotoxicity and tissue penetration. Br J Cancer 94: 863-869, 2006.

70. http://www.clinicaltrials.gov/ct2/results?term=bafilomycin\& Search=Search [accessed 19/12/2013]

71. Elmarakby AA, Ibrahim AS, Faulkner J, Mozaffari MS, Liou GI and Abdelsayed R: Tyrosine kinase inhibitor, genistein, reduces renal inflammation and injury in streptozotocin-induced diabetic mice. Vascul Pharmacol 55: 149-156, 2011.

72. Zhong WW, Liu Y and Li CL: Mechanisms of genistein protection on pancreas cell damage in high glucose condition. Intern Med 50: 2129-2134, 2011.

73. Hettiarachchi KD, Zimmet PZ and Myers MA: The effects of repeated exposure to sub-toxic doses of plecomacrolide antibiotics on the endocrine pancreas. Food Chem Toxicol 44: 1966-1977, 2006.

74. Myers MA, Hettiarachchi KD, Ludeman JP, Wilson AJ, Wilson CR and Zimmet PZ: Dietary microbial toxins and type 1 diabetes. Ann NY Acad Sci 1005: 418-422, 2003.

75. Lammi N, Karvonen M and Tuomilehto J: Do microbes have a causal role in type 1 diabetes? Med Sci Monit 11: RA63-RA69, 2005.

76. Klein CB and King AA: Genistein genotoxicity: critical considerations of in vitro exposure dose. Toxicol Appl Pharmacol 224: 1-11, 2007.

77. Labbaye C, Spinello I, Quaranta MT, et al: A three-step pathway comprising PLZF/miR-146a/CXCR4 controls megakaryopoiesis. Nat Cell Biol 10: 788-801, 2008.

78. Zhang W and Liu HT: MAPK signal pathways in the regulation of cell proliferation in mammalian cells. Cell Res 12: 9-18, 2002.

79. Barker $\mathrm{N}$ and Clevers $\mathrm{H}$ : Mining the Wnt pathway for cancer therapeutics. Nat Rev Drug Discov 5: 997-1014, 2006.

80. Sennoune SR, Luo D and Martinez-Zaguilan R: Plasmalemmal vacuolar-type $\mathrm{H}^{+}$-ATPase in cancer biology. Cell Biochem Biophys 40: 185-206, 2004.

81. Huang Y, Noble NA, Zhang J, Xu C and Border WA: Renin-stimulated TGF-beta1 expression is regulated by a mitogen-activated protein kinase in mesangial cells. Kidney Int 72: 45-52, 2007.

82. Balakumar P and Jagadeesh G: Potential cross-talk between (pro)renin receptors and Wnt/frizzled receptors in cardiovascular and renal disorders. Hypertens Res 34: 1161-1170, 2011. 